\title{
Cyclopolymerization of 1,6-Heptadienes
}

\author{
Catalyzed by Iron and Cobalt Complexes:
}

Synthesis of Polymers with trans- or cis-Fused

1,2-Cyclopentanediyl Groups Depending on the

\section{Catalyst}

Daisuke Takeuchi, Ryuichi Matsuura, Sehoon Park, and Kohtaro Osakada*

Chemical Resources Laboratory, Tokyo Institute of Technology, 4259 Nagatsuta, Yokohama, 226-8503, Japan 


\section{Experimental Section}

\section{General Method}

Dry solvents were purchased and used as received. Bis(imino)pyridine ligand and iron and cobalt complexes were prepared according to the reported procedure. ${ }^{1,2}$ 1,6Heptadiene was purchased and freeze-dried before use. 4-tert-Butyldimethylsiloxy-1,6heptadiene ${ }^{3}$ and 9,9-diallylfluorene ${ }^{4}$ were synthesized according to the reported procedure. NMR $\left({ }^{1} \mathrm{H}\right.$ and $\left.{ }^{13} \mathrm{C}\right)$ spectra were recorded on a Varian Mercury 300 or JEOL JNM-500 spectrometer. The peaks were referenced to $\mathrm{C}_{2} \mathrm{H}_{2} \mathrm{Cl}_{4}$ in the $\mathrm{C}_{2} \mathrm{D}_{2} \mathrm{Cl}_{4}$ solvent ( $\delta 5.91$ ) for ${ }^{1} \mathrm{H}$ and $\mathrm{C}_{2} \mathrm{D}_{2} \mathrm{Cl}_{4}$ ( $\delta 74.2$ ) for ${ }^{13} \mathrm{C}$. Molecular weight of the polymer was estimated by either ${ }^{1} \mathrm{H}$ NMR or Gel permeation chromatography (GPC). GPC was performed at $40{ }^{\circ} \mathrm{C}$ on a JASCO high-speed liquid chromatograph system equipped with a differential refractometer detector and a variable-wavelength UV-vis detector, using $\mathrm{CHCl}_{3}$ as eluent at a flow rate of $1.0 \mathrm{~mL} \mathrm{~min}^{-1}$ with Shodex-806L column or at $152{ }^{\circ} \mathrm{C}$ on a TOSOH HPLC-8121GPC/HT equipped with a FT-IR detector, using orthodichlorobenzene as eluent.

\section{1) Polymerization of 1,6-heptadiene by iron complex}

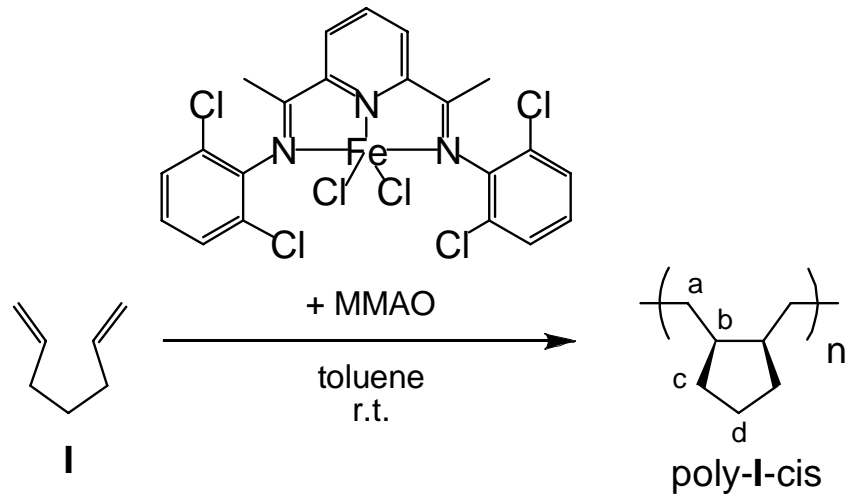

Typically, to a 25-mL Schlenk flask containing a toluene solution $(0.92 \mathrm{~mL})$ of Fe complex ${ }^{1}$ (12 $\mu \mathrm{mol}, 6.9 \mathrm{mg}$ ) was successively added a toluene solution of MMAO (0.28 mL, $0.6 \mathrm{mmolAl})$ and 1,6-heptadiene $(1.2 \mathrm{mmol}, 0.16 \mathrm{~mL})$ by a syringe, and the mixture was stirred at room temperature for $5 \mathrm{~h}$. The reaction mixture was quenched by 
adding EtOH (ca. $1 \mathrm{~mL}$ ). The produced polymer was isolated by pouring the reaction mixture into a large amount of $\mathrm{HCl} / \mathrm{methanol}$. The formed white precipitates formed were collected and dried in vacuo at room temperature. ${ }^{13} \mathrm{C}\left\{{ }^{1} \mathrm{H}\right\}$ NMR $\left(\mathrm{C}_{2} \mathrm{D}_{2} \mathrm{Cl}_{4}\right)$ : $\delta$ 23.0 (cis -d), 24.3 (trans -d), 28.6, 28.7, 28.8, 28.9 (cis -a), 30.9, 31.1 (cis-c), 32.6, 32.9 (trans -a), 34.5, 34.8 (trans-c), 43.1 43.3, 43.6, 43.8 (cis -b), and 46.4, 46.8 (trans -b). $T_{\mathrm{g}}=0.4^{\circ} \mathrm{C}, T_{\mathrm{m}}=133^{\circ} \mathrm{C}\left(\right.$ Heat of Fusion $\left.=22.1 \mathrm{~J} \mathrm{~g}^{-1}\right)$

\section{2) Polymerization of 1,6-heptadiene by cobalt complex}

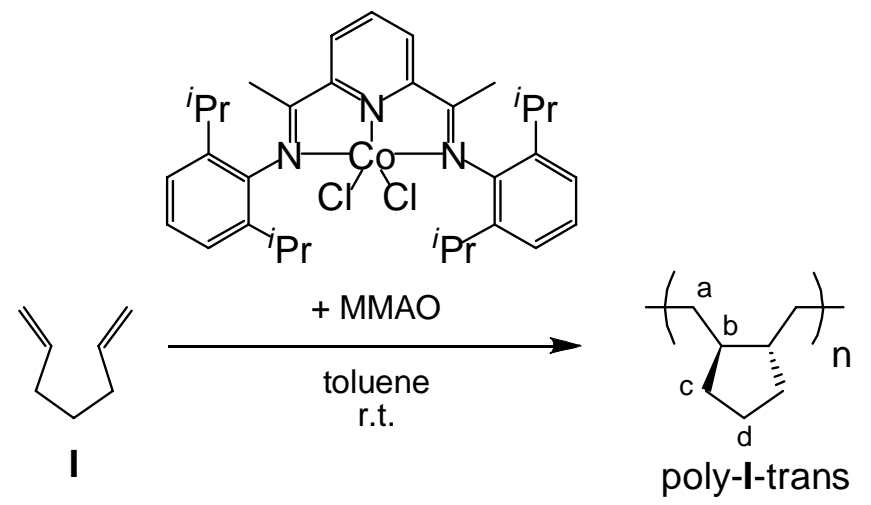

Typically, to a 25-mL Schlenk flask containing Co complex 2 (12 $\mu \mathrm{mol}, 7.3 \mathrm{mg}$ ) was successively added a toluene solution of MMAO (1.2 mL, $2.6 \mathrm{mmolAl})$ and 1,6heptadiene (1.2 mmol, $0.16 \mathrm{~mL}$ ) by a syringe, and the mixture was stirred at room temperature for $5 \mathrm{~h}$. The reaction mixture was quenched by adding EtOH (ca. $1 \mathrm{~mL}$ ). The produced polymer was isolated by pouring the reaction mixture into a large amount of $\mathrm{HCl} /$ methanol. The formed white precipitates formed were collected and dried in vacuo at room temperature. ${ }^{13} \mathrm{C}\left\{{ }^{1} \mathrm{H}\right\} \operatorname{NMR}\left(\mathrm{C}_{2} \mathrm{D}_{2} \mathrm{Cl}_{4}\right): \delta 24.2(d), 32.5,32.6(a)$, 34.1, $34.3(c)$, and $46.3,46.7(b) . T_{\mathrm{g}}=3.2^{\circ} \mathrm{C}$ 


\section{3) Polymerization of 4-tert-butyldimethylsiloxy-1,6-heptadiene by iron complex}

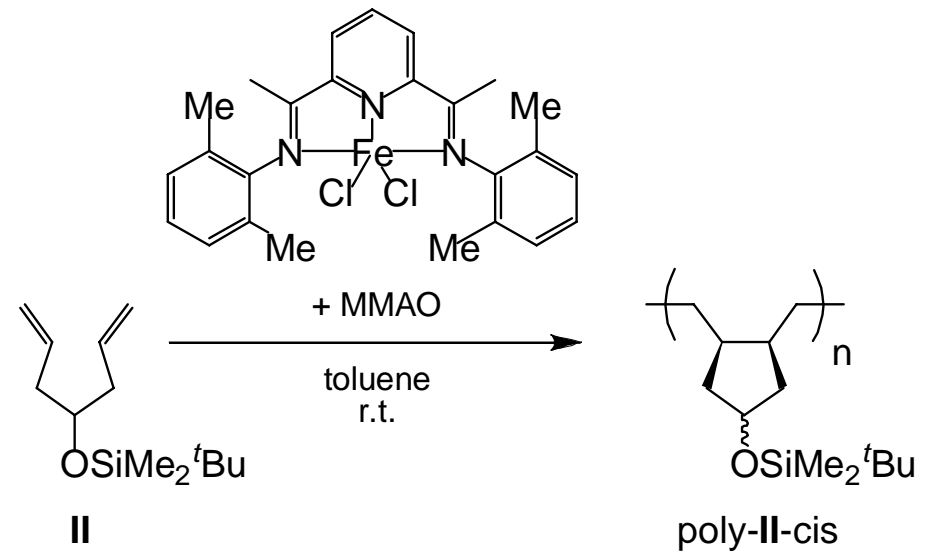

Typically, to a 25-mL Schlenk flask containing a toluene solution $(0.92 \mathrm{~mL})$ of Fe complex ${ }^{2}$ (12 $\mu \mathrm{mol}, 6.0 \mathrm{mg}$ ) was successively added a toluene solution of MMAO (0.28 mL, 0.6 mmolAl) and 4-tert-butyldimethylsiloxy-1,6-heptadiene ${ }^{3}$ (1.2 mmol, 272 $\mathrm{mg}$ ) by a syringe, and the mixture was stirred at room temperature for $5 \mathrm{~h}$. The reaction mixture was quenched by adding EtOH (ca. $1 \mathrm{~mL}$ ). The produced polymer was isolated by pouring the reaction mixture into a large amount of $\mathrm{HCl} /$ methanol. The formed white precipitates formed were collected and dried in vacuo at room temperature. ${ }^{13} \mathrm{C}\left\{{ }^{1} \mathrm{H}\right\}$ NMR $\left(\mathrm{C}_{2} \mathrm{D}_{2} \mathrm{Cl}_{4}\right): \delta-4.4\left(\mathrm{SiCH}_{3}\right), 18.1\left(\mathrm{SiCCH}_{3}\right), 26.2\left(\mathrm{CCH}_{3}\right), 29.4$ ( $\mathrm{CH}_{2}$ (main chain)), 40.9, $42.9(\mathrm{CH}), 41.6,41.9,42.1\left(\mathrm{CHCH}_{2} \mathrm{CH}\right)$, and 73.3, 73.4 (CHO).

5) Polymerization of 4-tert-butyldimethylsiloxy-1,6-heptadiene by cobalt complex

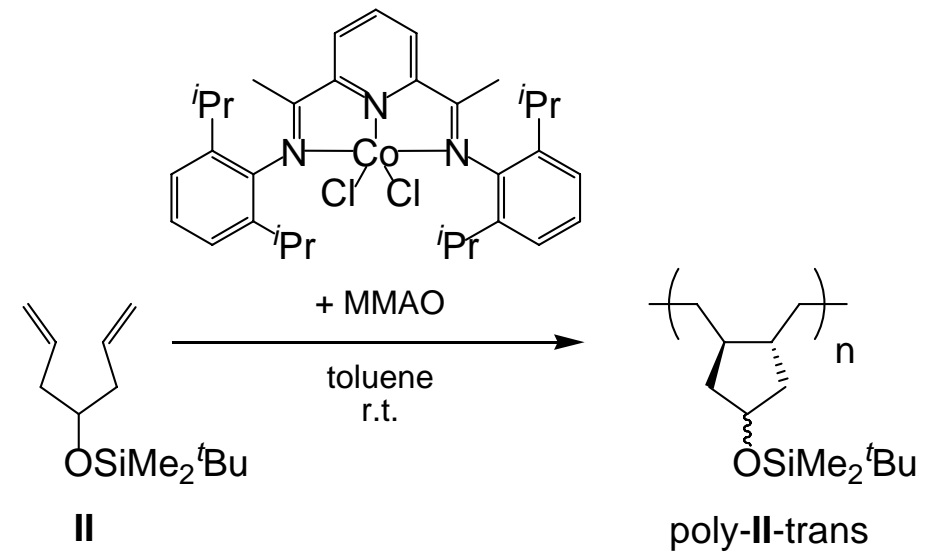


Typically, to a 25-mL Schlenk flask containing Co complex 2 (12 $\mu \mathrm{mol}, 7.3 \mathrm{mg})$ was successively added a toluene solution of MMAO (1.2 mL, $2.6 \mathrm{mmolAl})$ and 4-tertbutyldimetylsiloxy-1,6-heptadiene ${ }^{3}(1.2 \mathrm{mmol}, 295 \mathrm{mg})$ by a syringe, and the mixture was stirred at room temperature for $5 \mathrm{~h}$. The reaction mixture was quenched by adding EtOH (ca. $1 \mathrm{~mL}$ ). The produced polymer was isolated by pouring the reaction mixture into a large amount of $\mathrm{HCl} /$ methanol. The formed white precipitates formed were collected and dried in vacuo at room temperature. ${ }^{13} \mathrm{C}\left\{{ }^{1} \mathrm{H}\right\}$ NMR $\left(\mathrm{C}_{2} \mathrm{D}_{2} \mathrm{Cl}_{4}\right): \delta$-4.4 ( $\left.\mathrm{SiCH}_{3}\right), 18.1\left(\mathrm{SiCCH}_{3}\right), 26.2\left(\mathrm{CCH}_{3}\right), 33.9-34.8\left(\mathrm{CH}_{2}\right.$ (main chain)), 42.5, 42.7 $\left(\mathrm{CHCH}_{2} \mathrm{CH}\right), 43.7,44.3,45.2(\mathrm{CH})$, and $73.4(\mathrm{CHO})$.

\section{6) Polymerization of 9,9-diallylfluorene by iron complex}

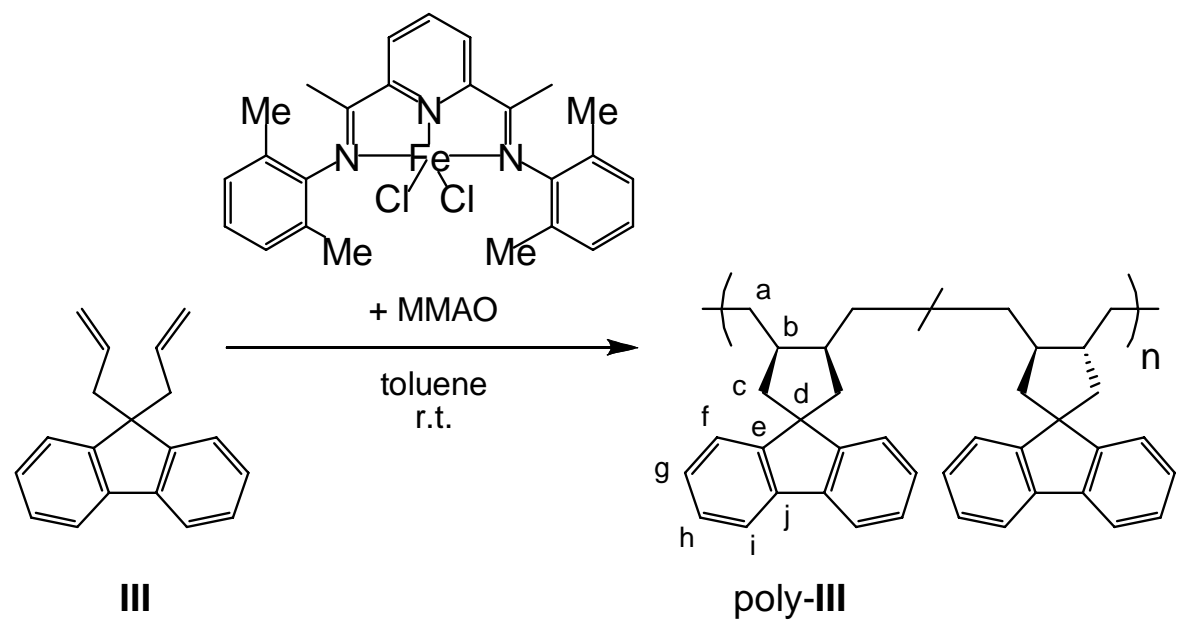

Typically, to a 25-mL Schlenk flask containing a toluene solution $(0.92 \mathrm{~mL})$ of Fe complex ${ }^{2}$ (12 $\mu$ mol, $6.0 \mathrm{~g}$ ) was successively added a toluene solution of MMAO (0.28 mL, $0.6 \mathrm{mmolAl})$ and 9,9-diallylfluorene 4 (1.2 mmol, $295 \mathrm{mg})$ by a syringe, and the mixture was stirred at room temperature for $5 \mathrm{~h}$. The reaction mixture was quenched by adding EtOH (ca. $1 \mathrm{~mL}$ ). The produced polymer was isolated by pouring the reaction mixture into a large amount of $\mathrm{HCl} /$ methanol. The formed white precipitates formed were collected and dried in vacuo at room temperature. ${ }^{13} \mathrm{C}\left\{{ }^{1} \mathrm{H}\right\}$ 
NMR $\left(\mathrm{C}_{2} \mathrm{D}_{2} \mathrm{Cl}_{4}\right): \delta 29.9$ (cis-a), 32.9 (trans-a), 43.2 (cis-b), 44.0 (cis-c), 45.5 (transc), 48.6 (trans-b), 56.0 (trans-d), 57.3 (cis-d), 119.7 (cis- and trans-i), 122.9 (trans-f), 123.2 (cis-f), 127.0 (cis- and trans-h), 127.8 (cis- and trans-g), 139.6 (cis-j), 140.0 (trans-j), 153.5 (cis-e), and 155.7 (trans-e).

\section{6) Determination of chain end structure}

The ${ }^{1} \mathrm{H}$ NMR spectrum of poly-I (run $1, M_{\mathrm{n}}=14000$ ) shows the signal at $\delta 5.30$ 5.50, which is assigned to the vinylene hydrogens of 2- and/or 3-cyclohexenyl groups (manuscript, p. 1, left column, line 28-31, Fig. S1). We proposed the polymer end structure A and B (Scheme S1). Scheme S1 shows the plausible pathway for formation of the end group. The cyclization via 2,1-insertion after 2,1-insertion of the first vinyl group, included in the pathway, is regarded to be a sterically unfavorable process in discussion of the mechanism of Zr-catalyzed cyclopolymerization of 1,6-diene. ${ }^{5}$ One of the reviewers suggested another possible scheme for the reaction, shown in Scheme S2, which results in the end groups, C-E in Scheme S2. 1,2-Insertion of a vinyl group of the diene may be probable because 1,2-insertion of propylene into the Fe-polymer bond was reported to occur in part in polymerization of propylene catalyzed by the Fe complex. ${ }^{6}{ }^{13} \mathrm{C}\left\{{ }^{1} \mathrm{H}\right\}$ NMR spectra and those with DEPT technique of poly-I (run 2, 3 in Table $1, M_{\mathrm{n}}=3000, M_{\mathrm{n}}=4300$ ) do not exhibit any signals assignable to methyl $\left(\mathrm{CH}_{3}\right)$ carbons ( $\left.\delta 20-30\right)$ attached to cyclohexenyl group. Thus, the NMR data suggest the end structures A and B rather than C-E, although it is not easy to determine the end structures and mechanism for the chain transfer clearly at present. Molecular weight $\left(M_{\mathrm{n}}\right)$ estimated on the basis of ${ }^{1} \mathrm{H}$ NMR becomes half of the value presented in Table 1 when assuming the end group of the polymer is $\mathrm{D}$ and/or $\mathrm{E}$.

\section{References}

1. Changtao, Q; Xicheng, D; Jie, S. Organometallics 2003, 22, 4312. 
2. Small, B. L.; Brookhart, M. Macromolecules 1999, 32, 2120.

3. Newcombe. N. J. Org. Biomol. Chem. 2003, 1, 2173.

4. Kelley, C. J; Ghiorghis, A; Kauffman, J. M. J. Chem. Research, Synopses, 1997, 12, 446.

4. Hustad, P. D.; Tian, J.; Coates, G. W. J. Am. Chem. Soc. 2002, 124, 3614. (ref. 2 of the paper)

4. Pellecchia, C.; Mazzeo, M.; Pappalardo, D. Macromol. Rapid Commun. 1998, 19, 651. (ref. 13a of the paper)

\section{Scheme S1}

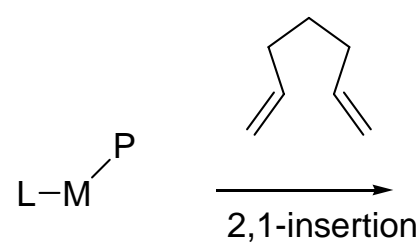<smiles>[M]CC(CC)(CP)CCC=C</smiles>

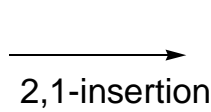<smiles>[AlH]C1CCCC(CP)C1</smiles>

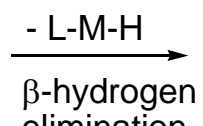<smiles>PCC1C=CCCC1</smiles>

A

or<smiles>PCC1CC=CCC1</smiles>

B 
Scheme S2
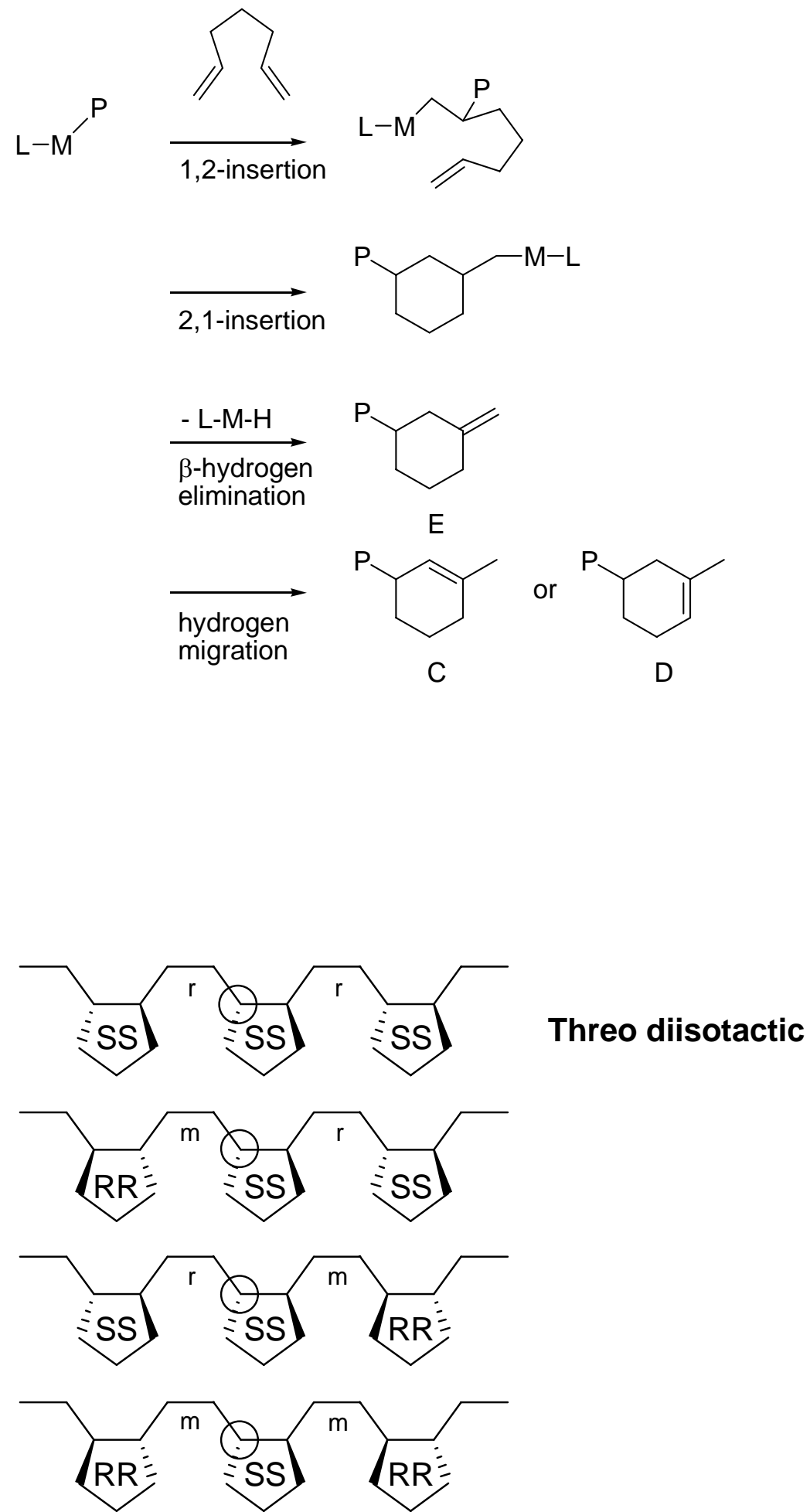

Chart S1. Tacticity and rr triads 


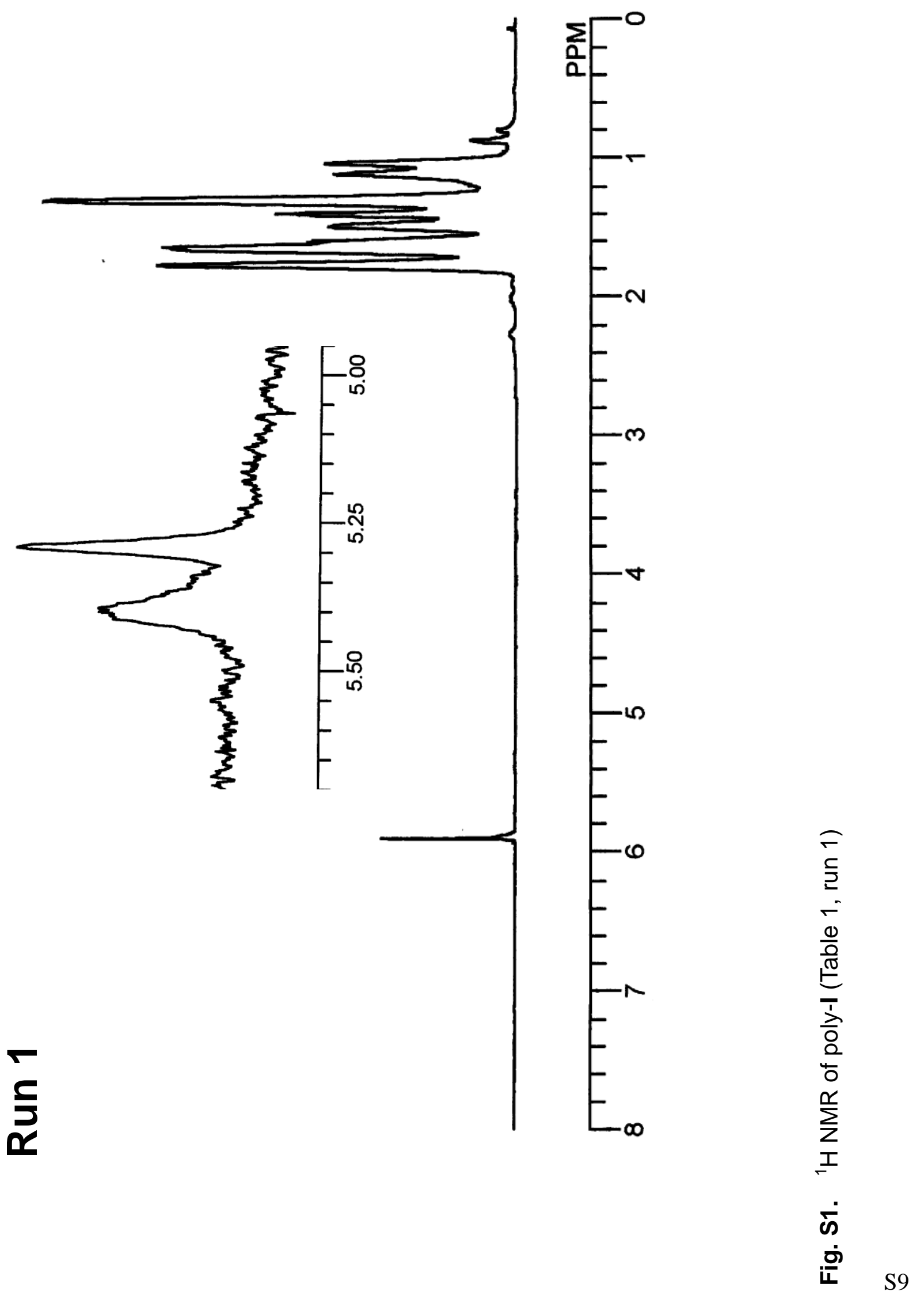




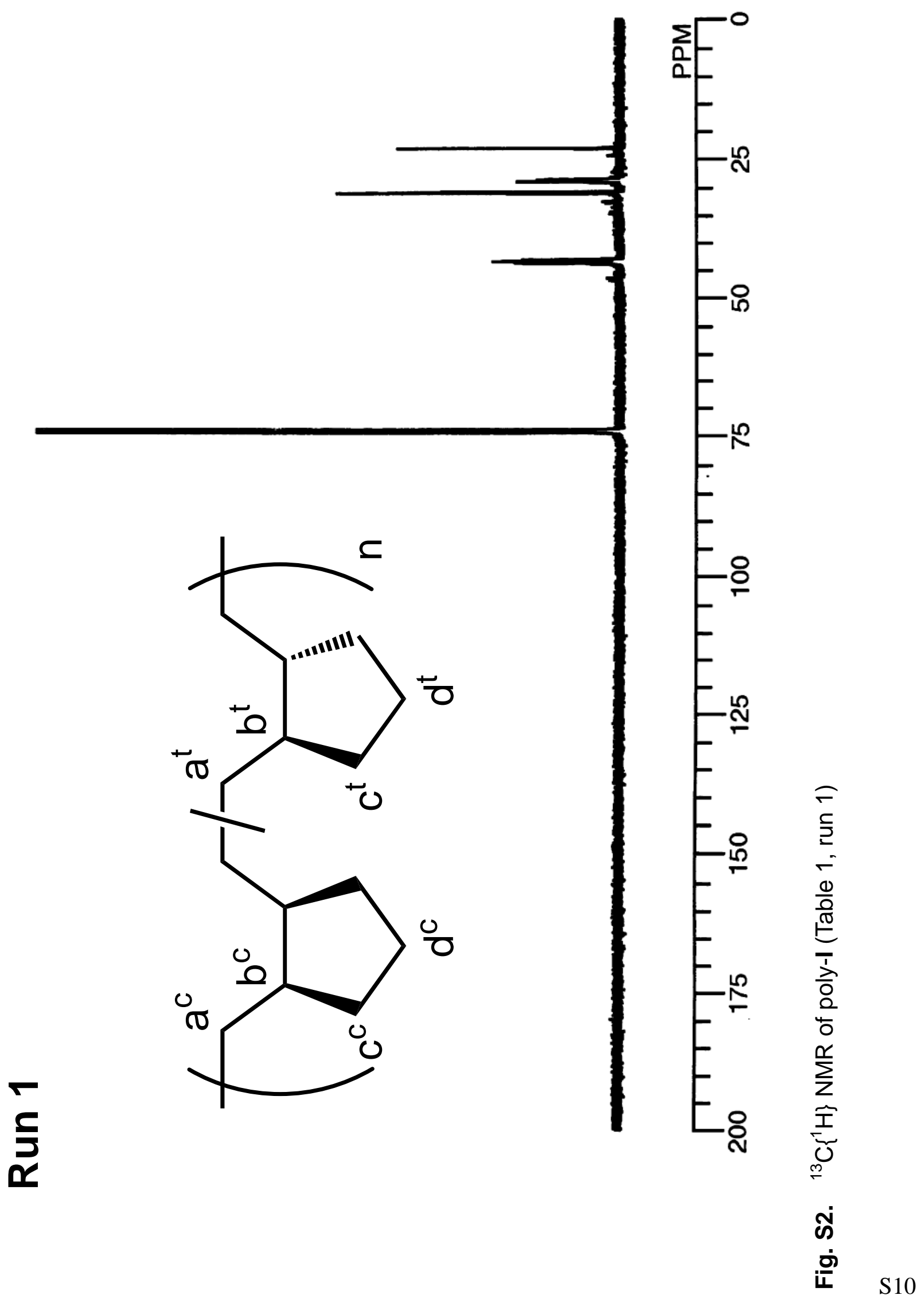




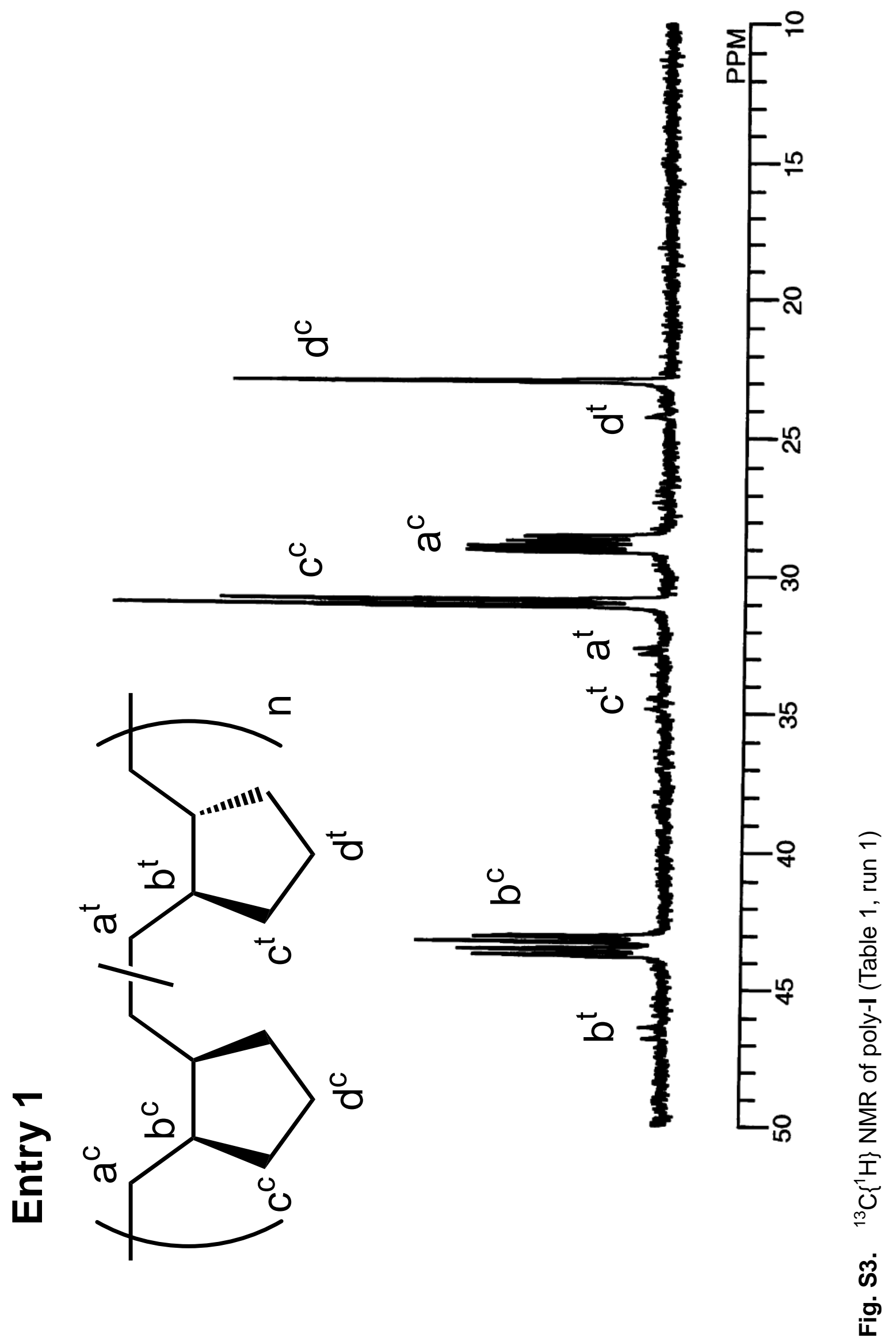




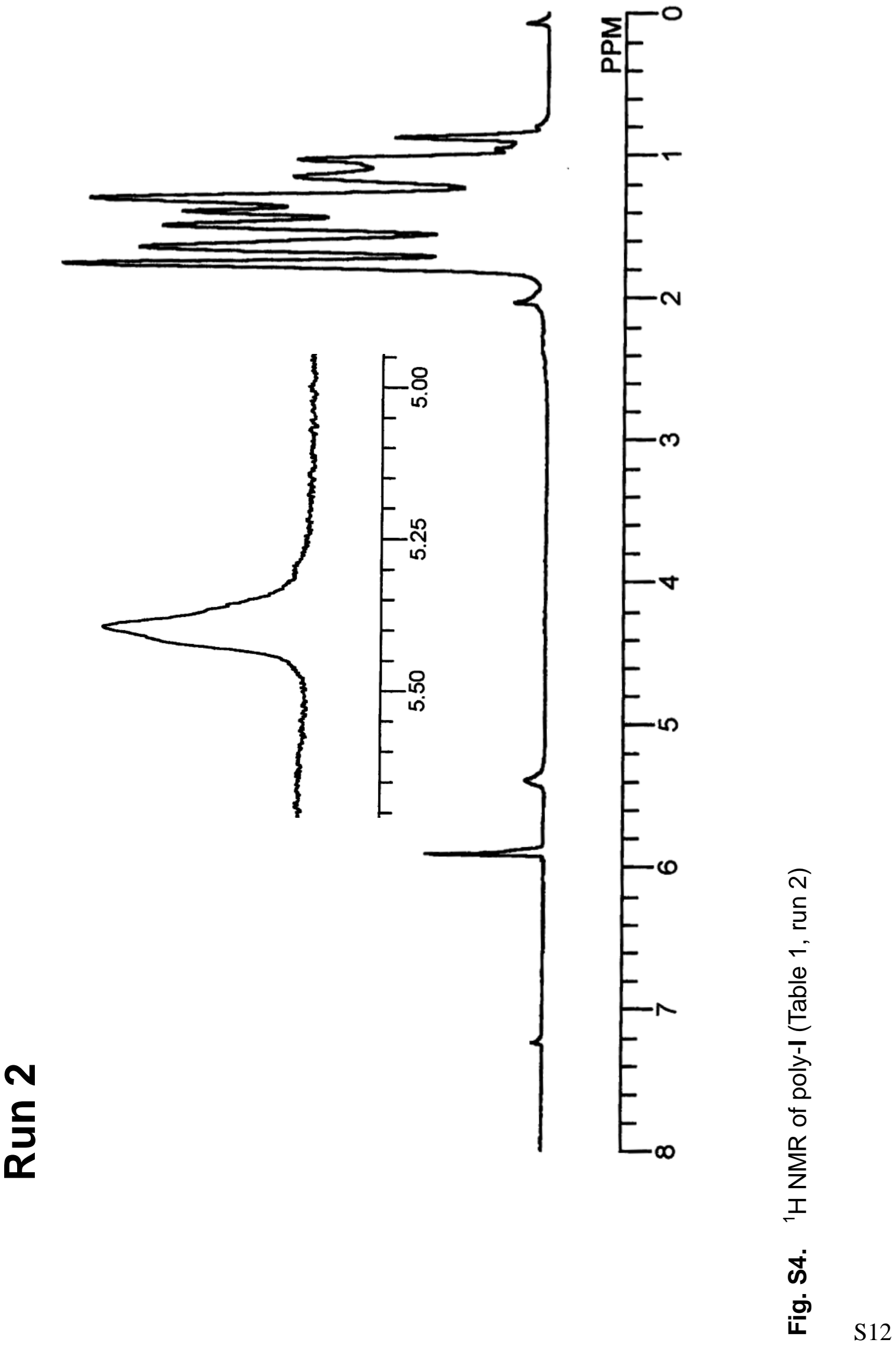




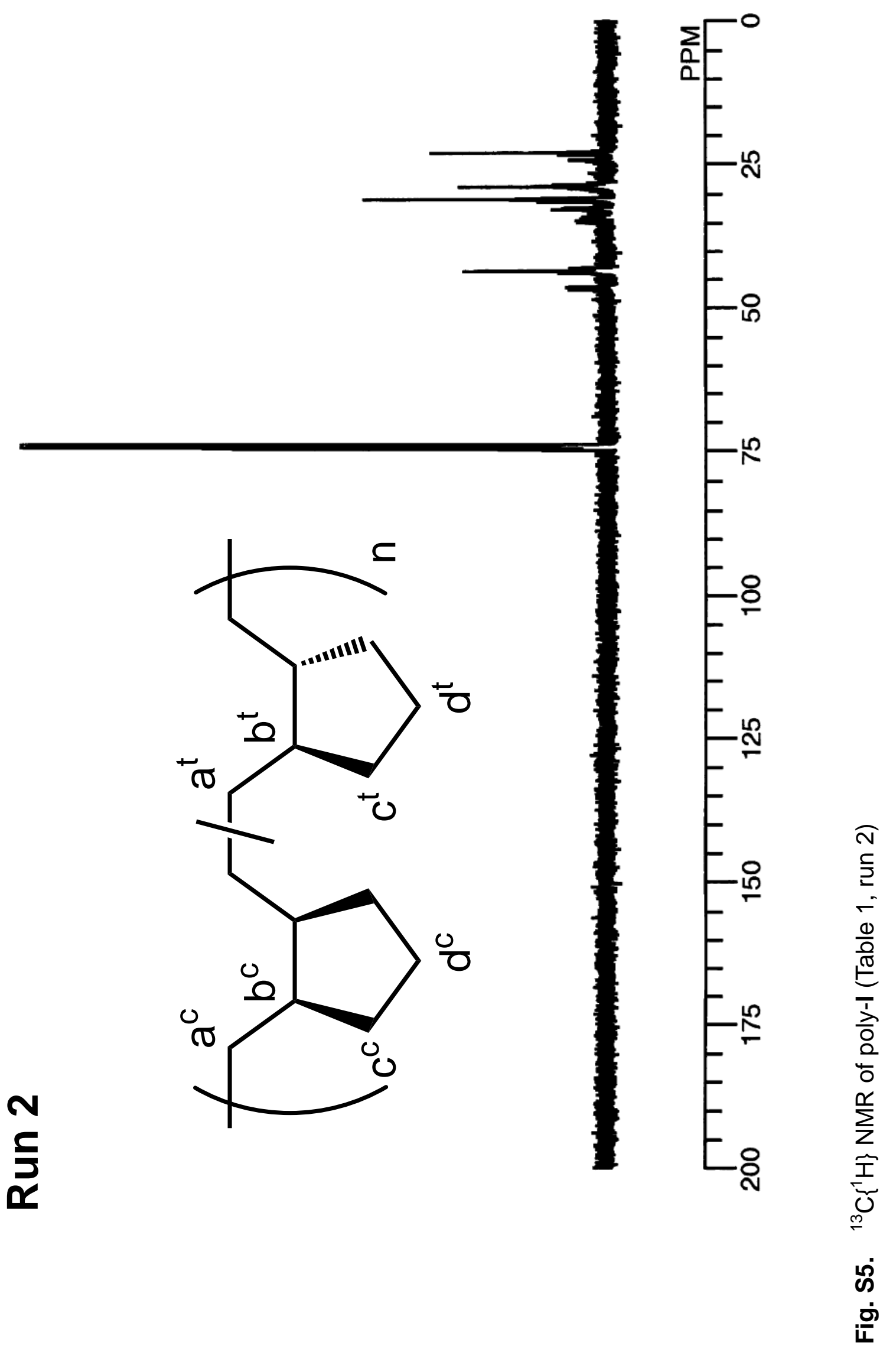

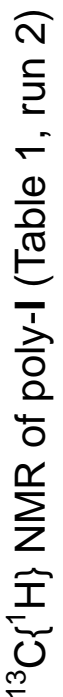

ฒ่

这 $\mathrm{S} 13$ 


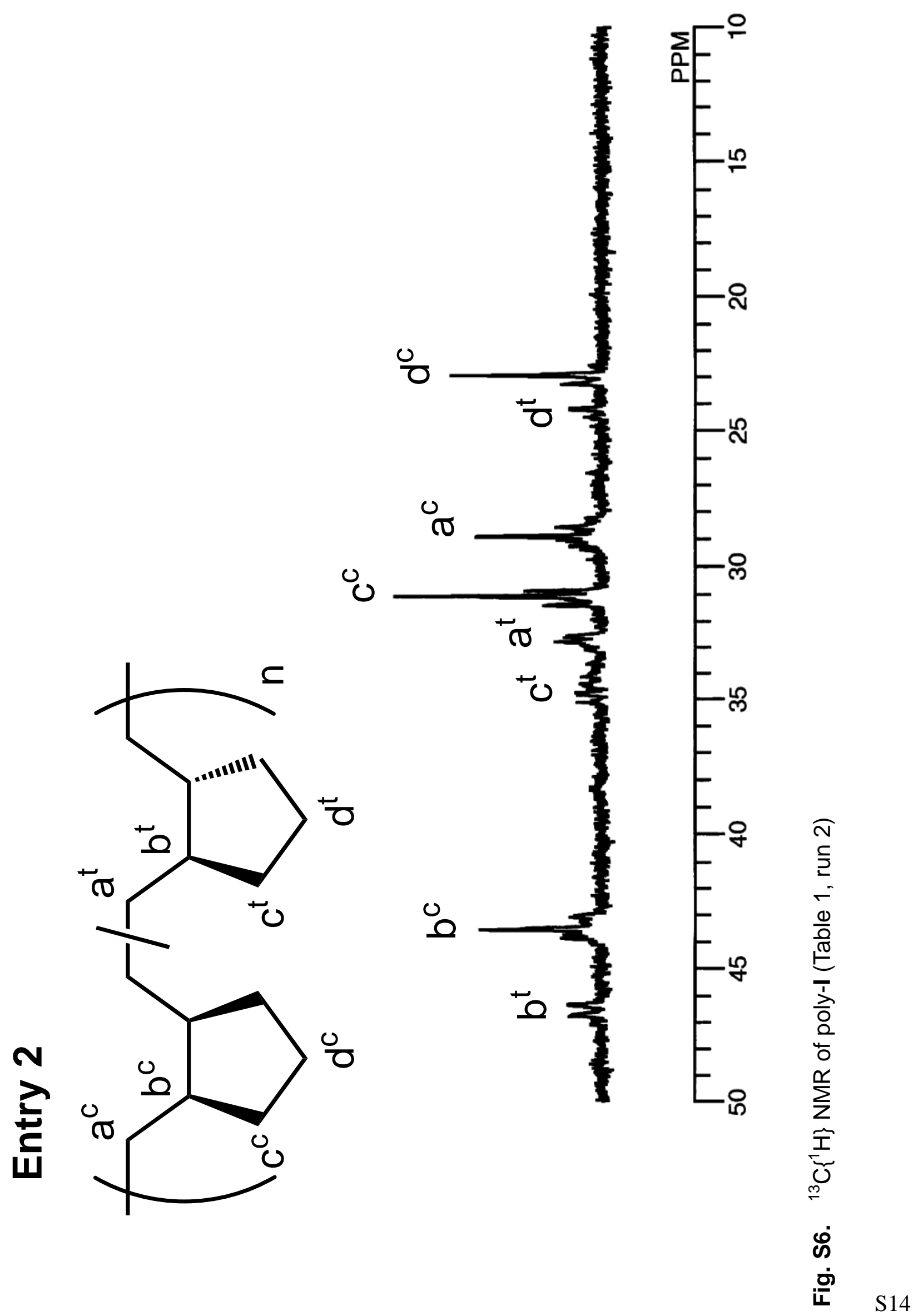




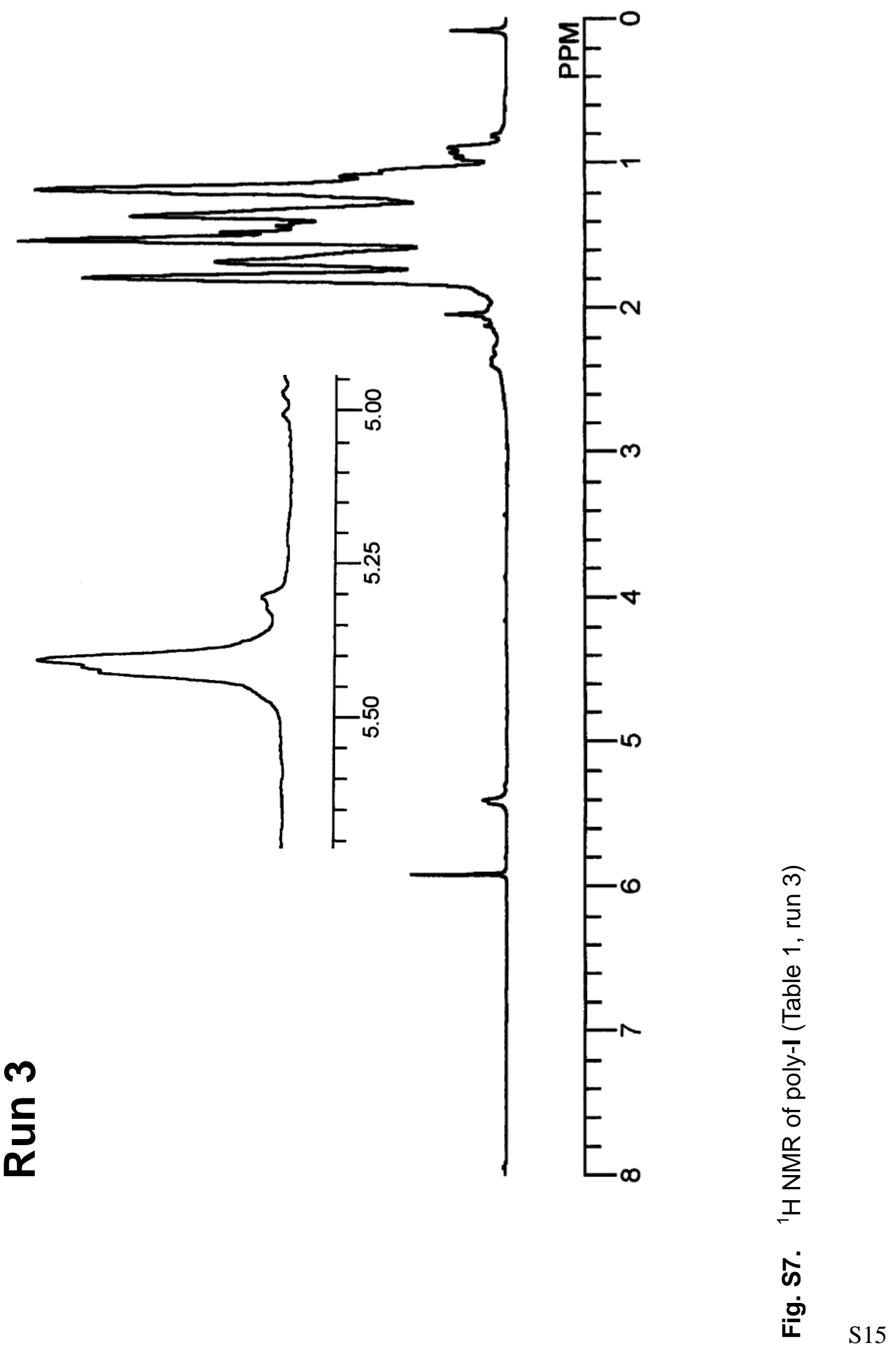




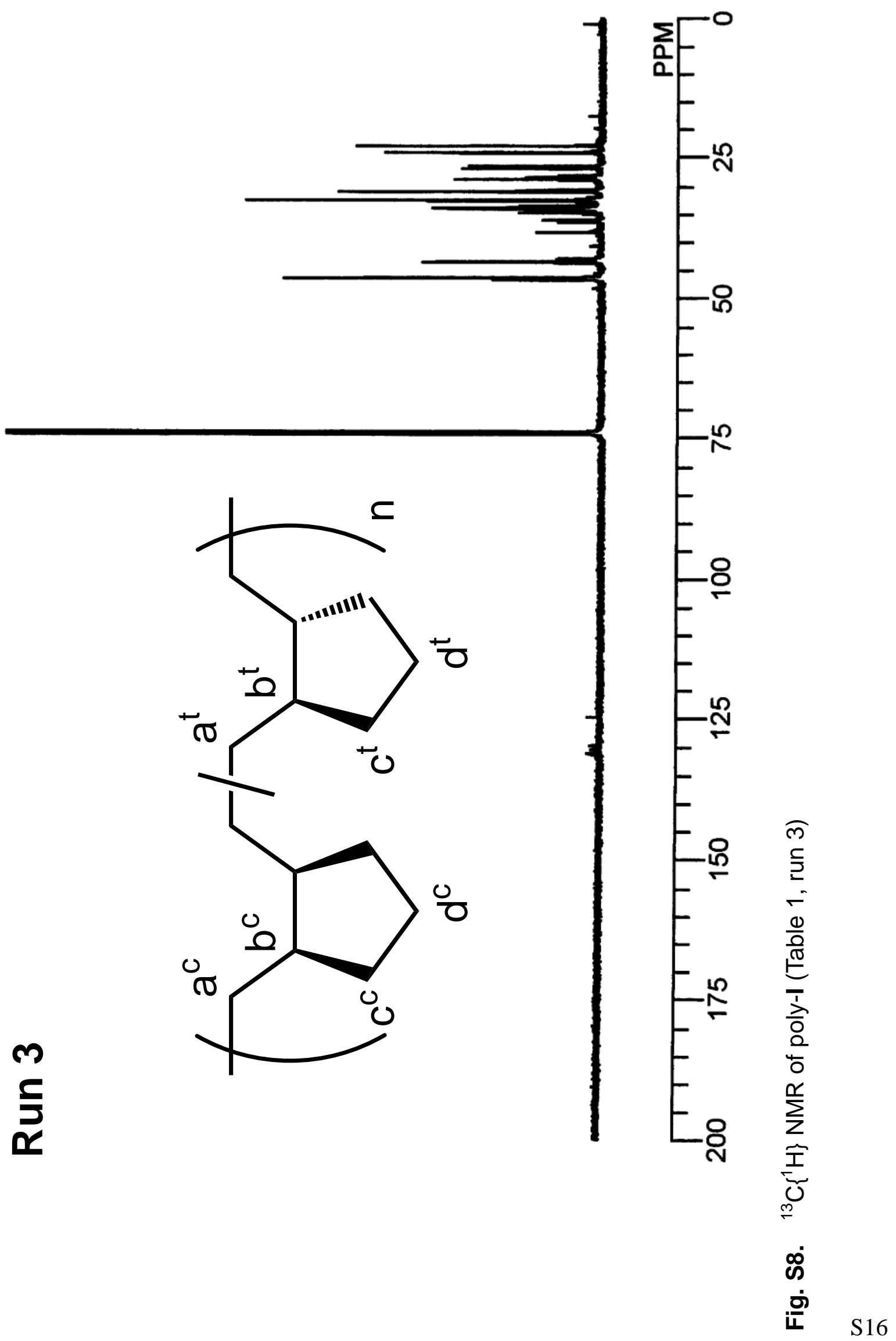



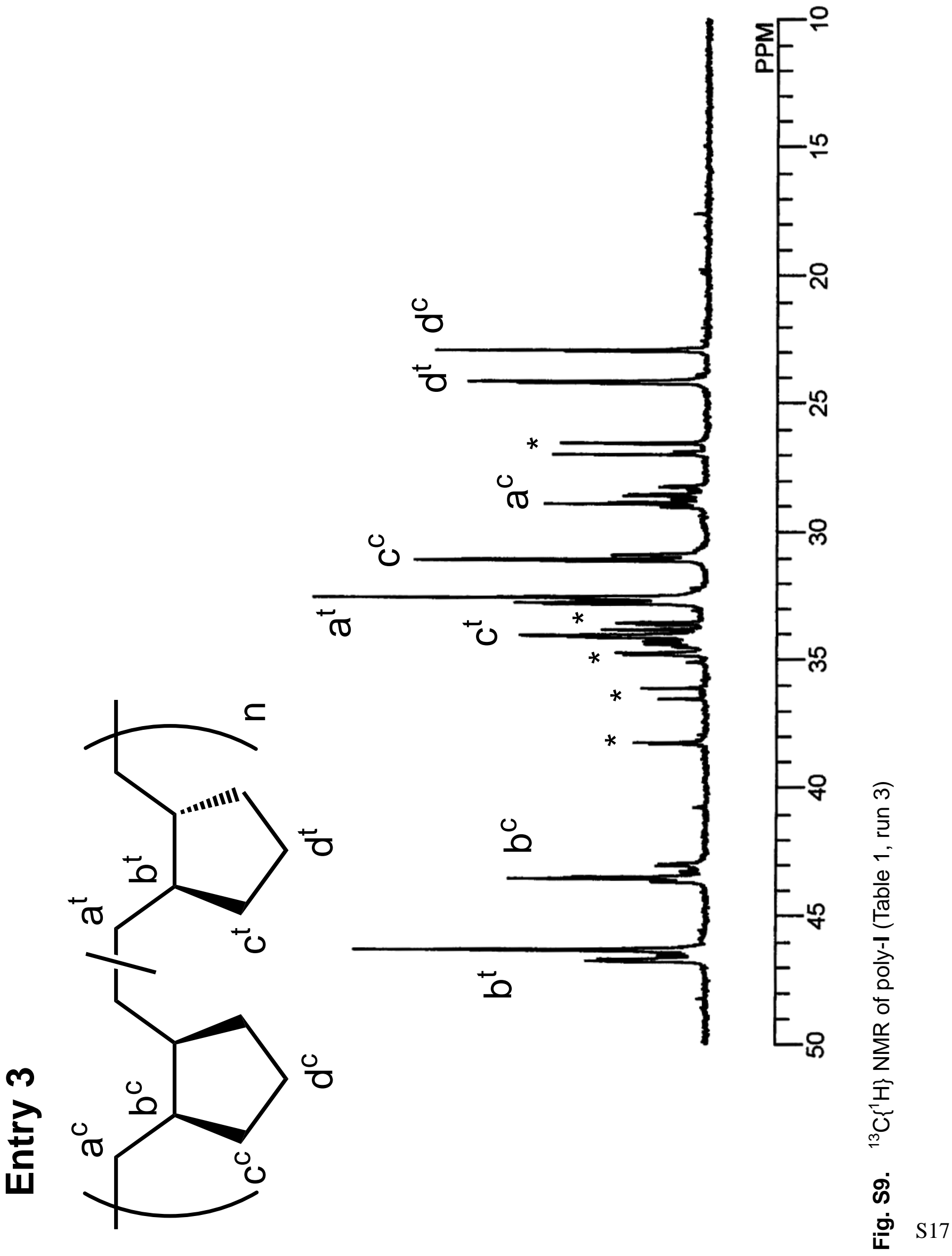


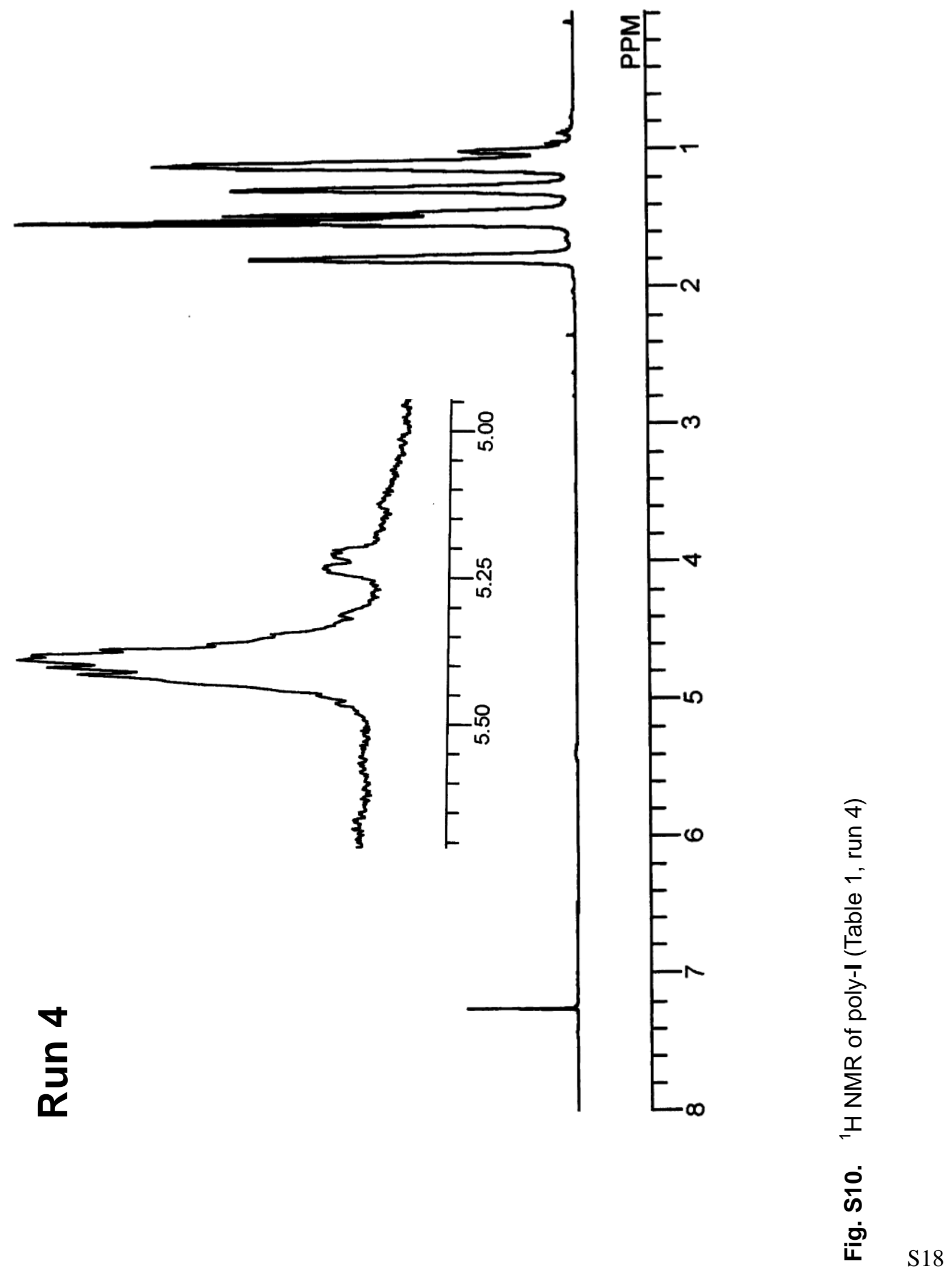




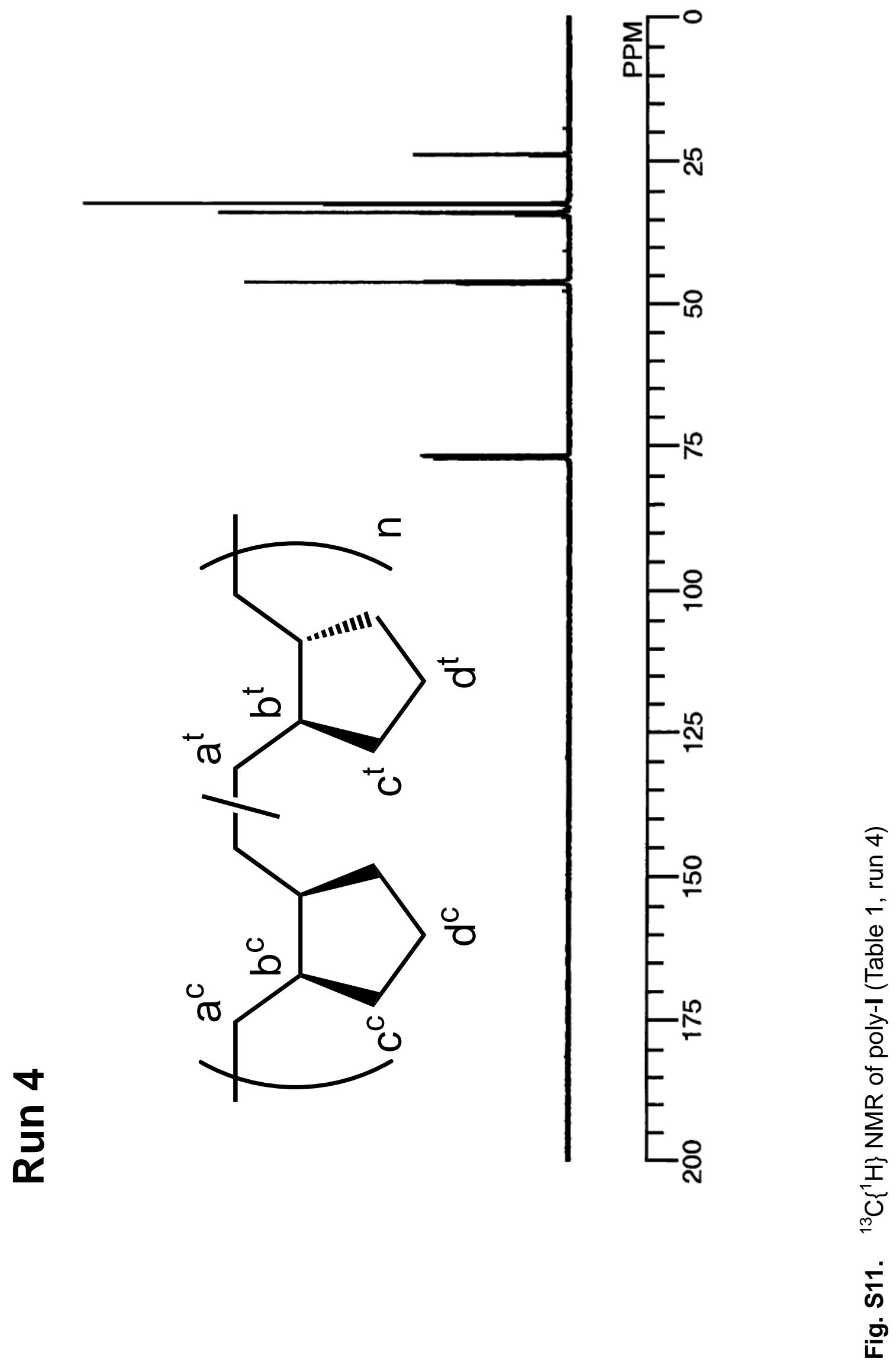




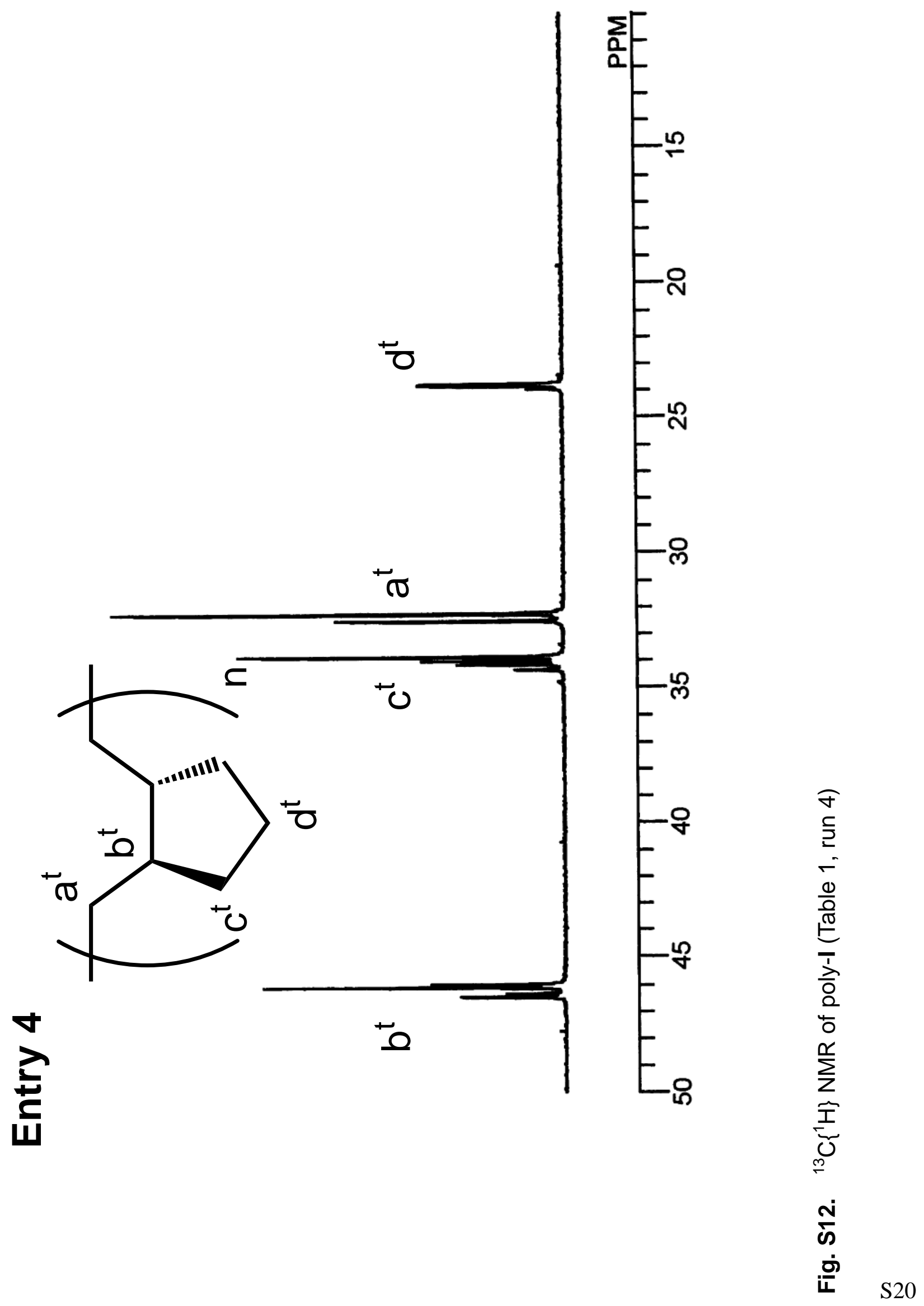




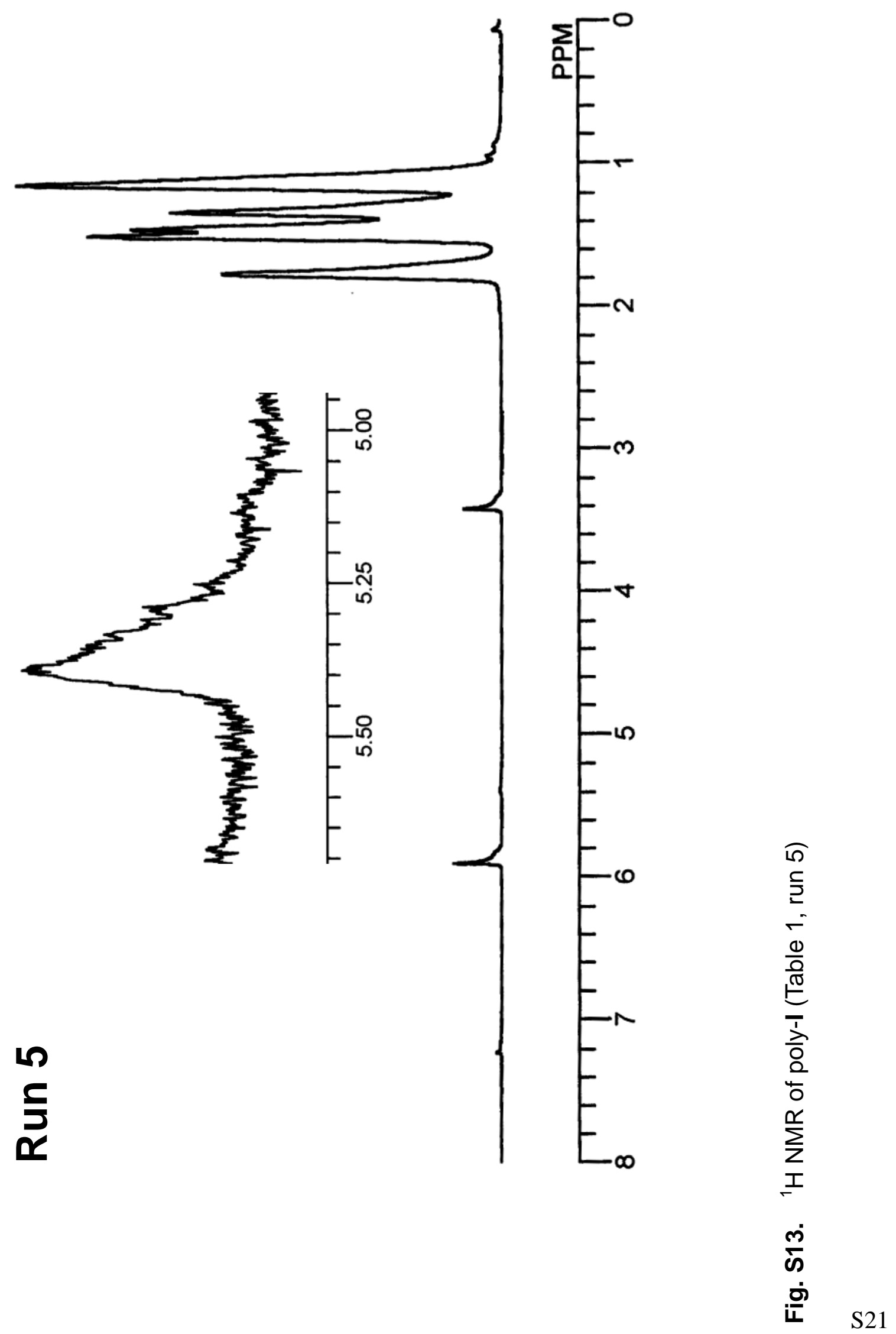




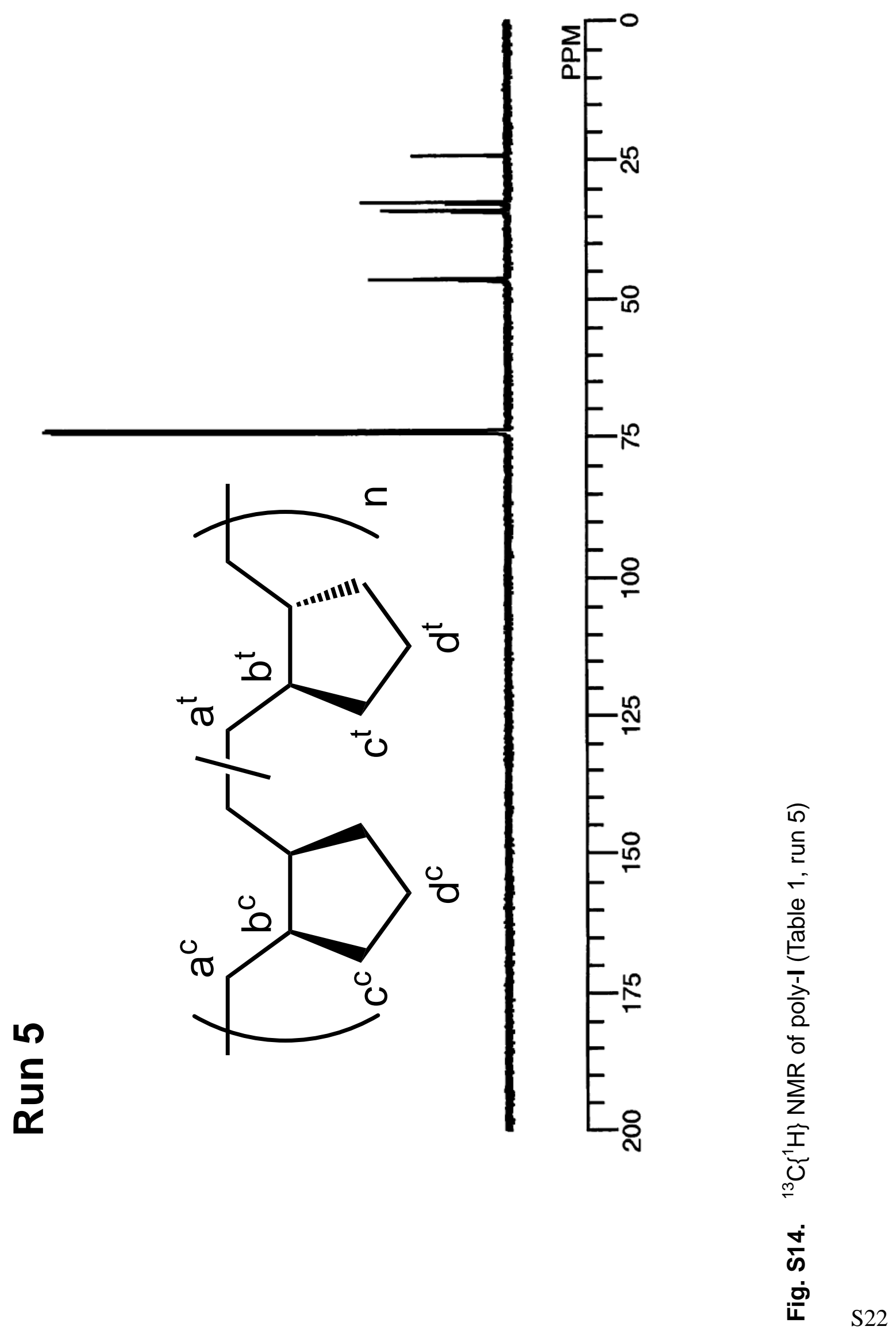




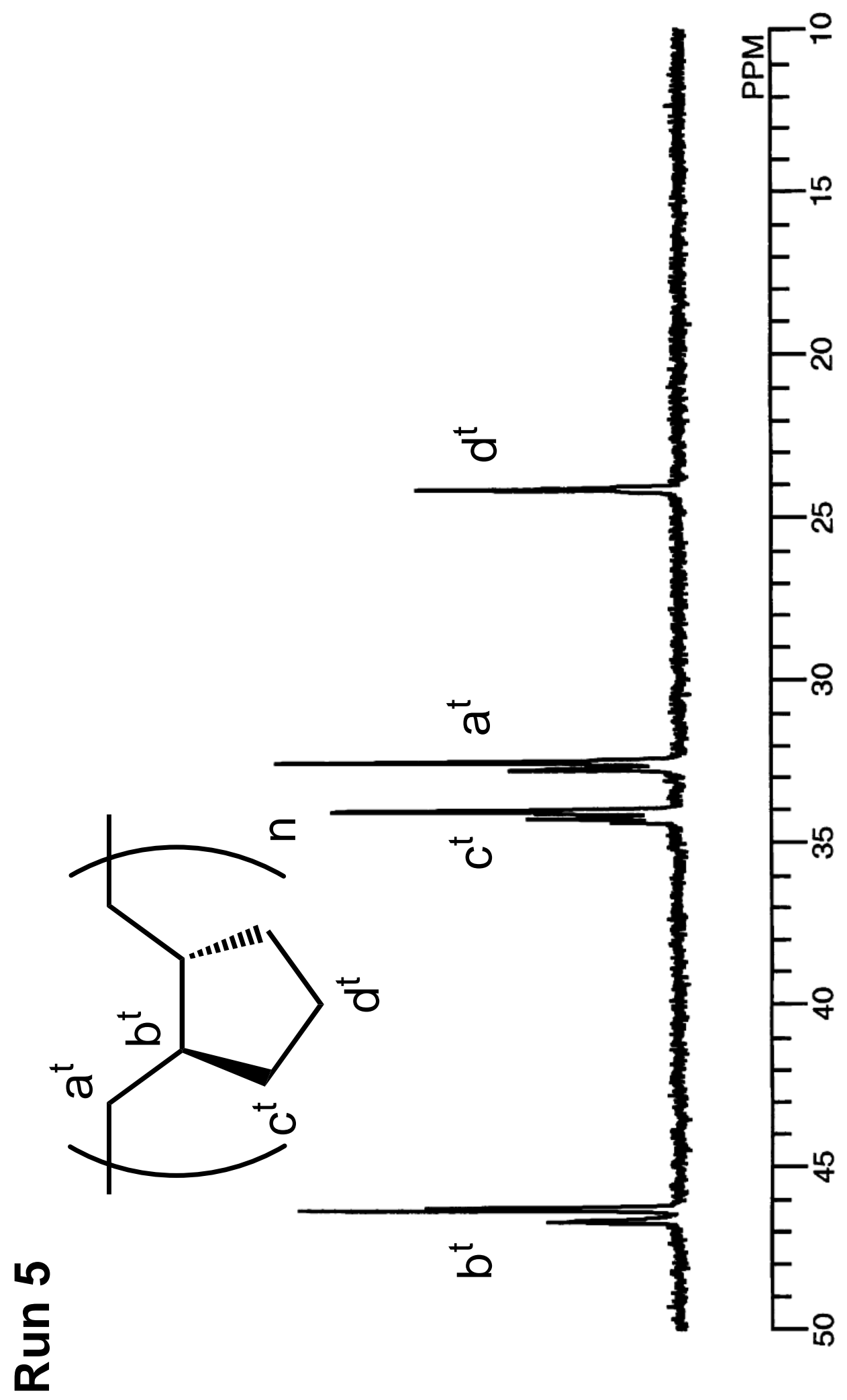




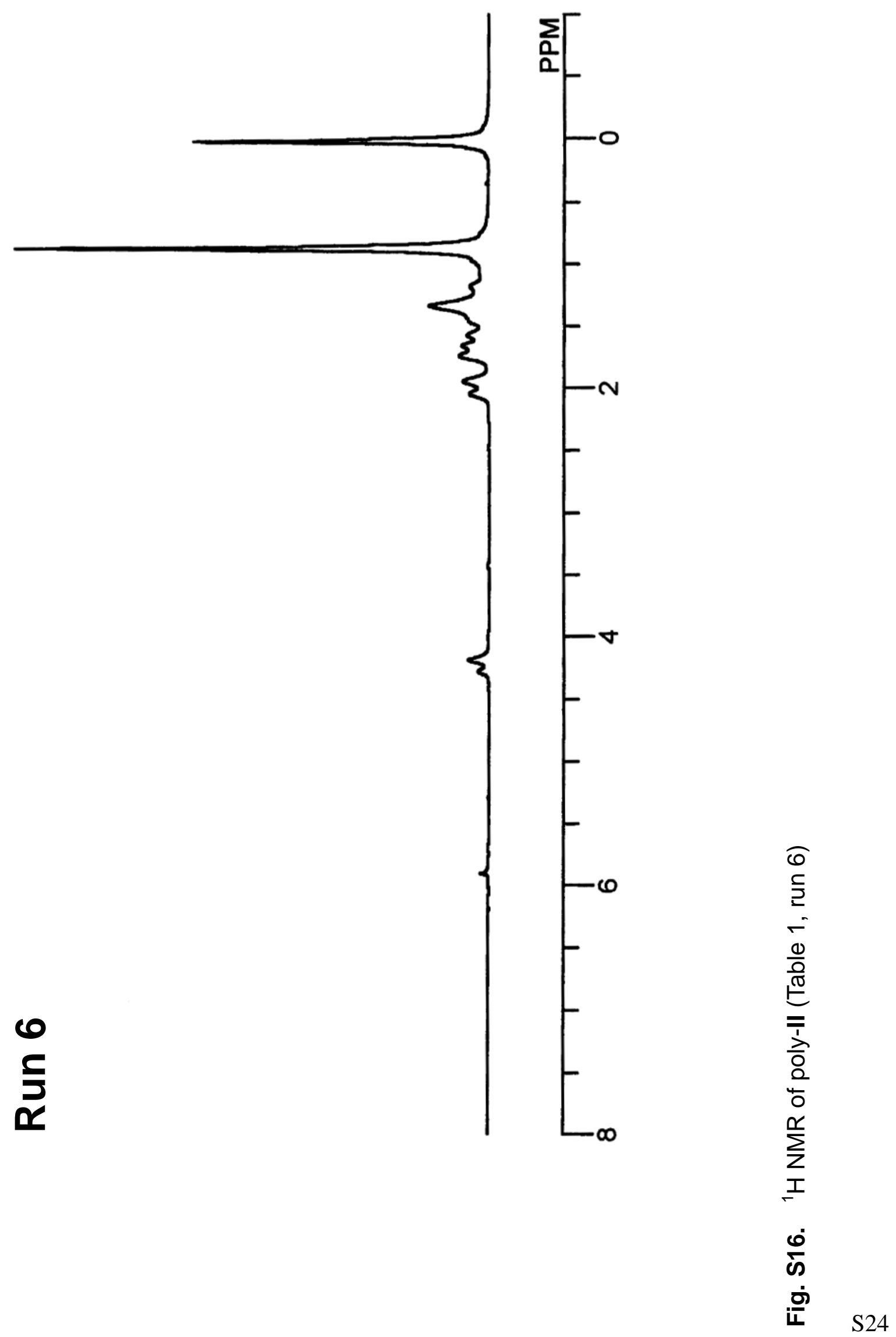



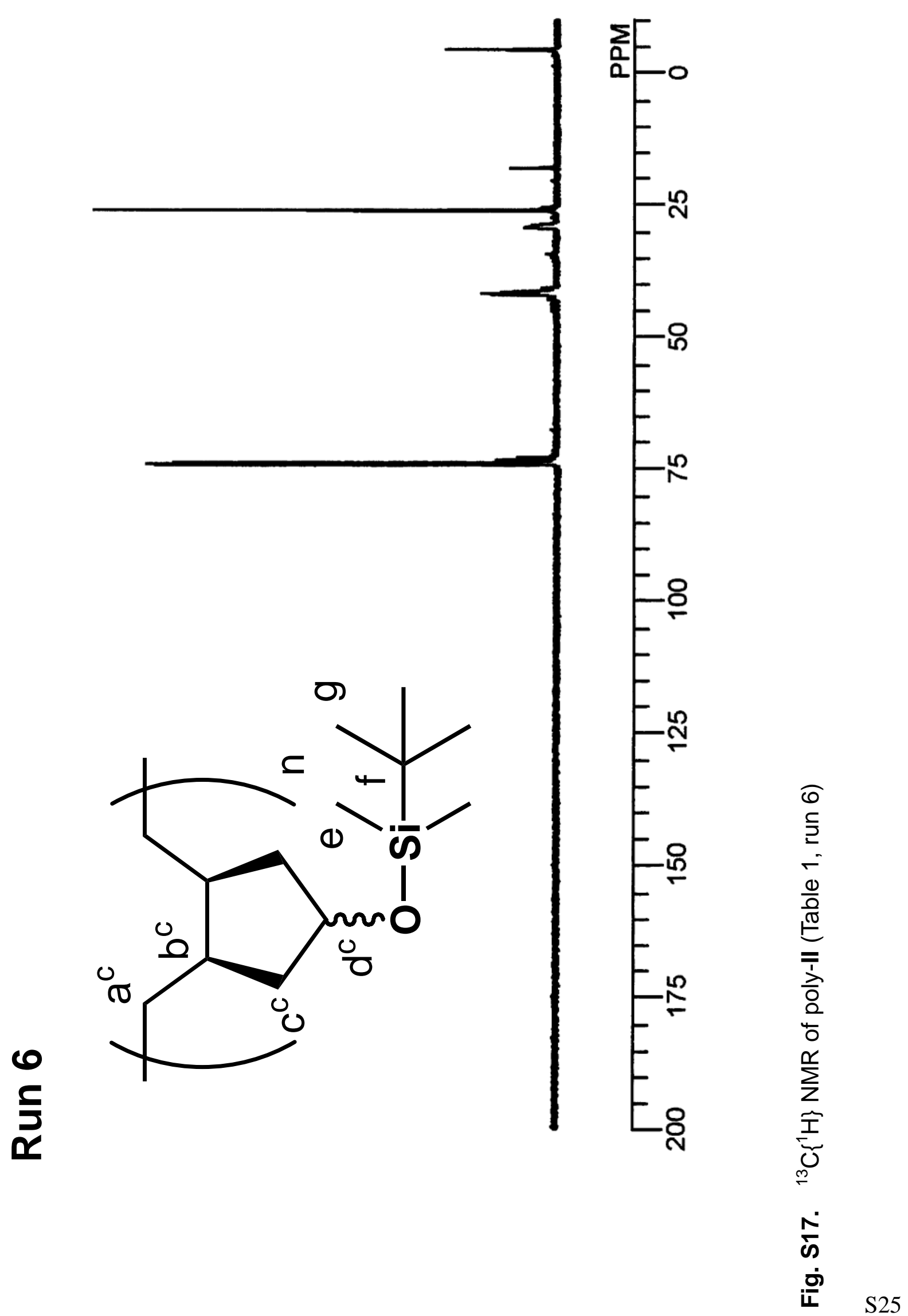


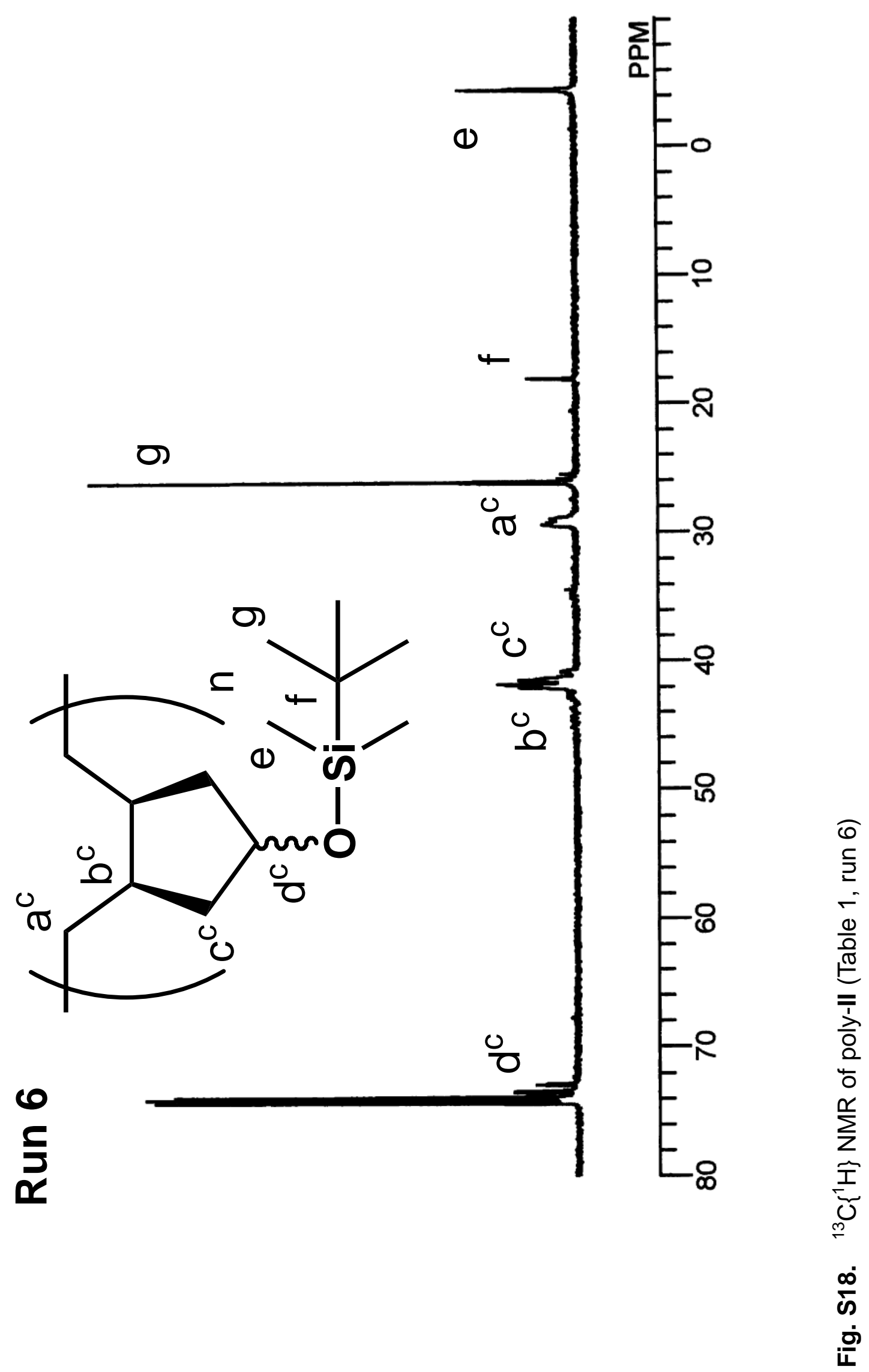

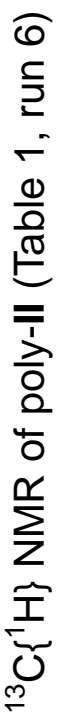

ज)

ํํㄴ S26 

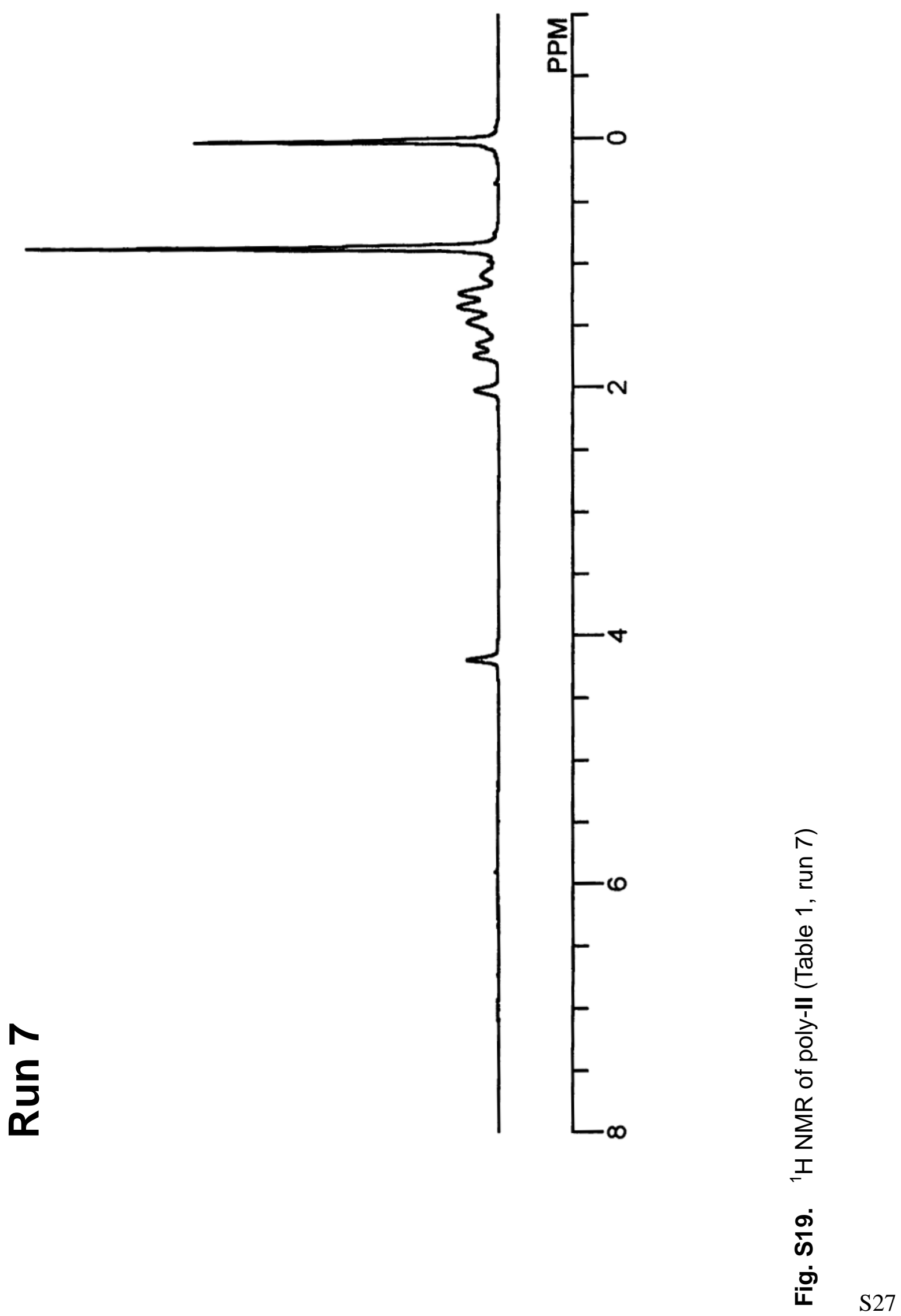


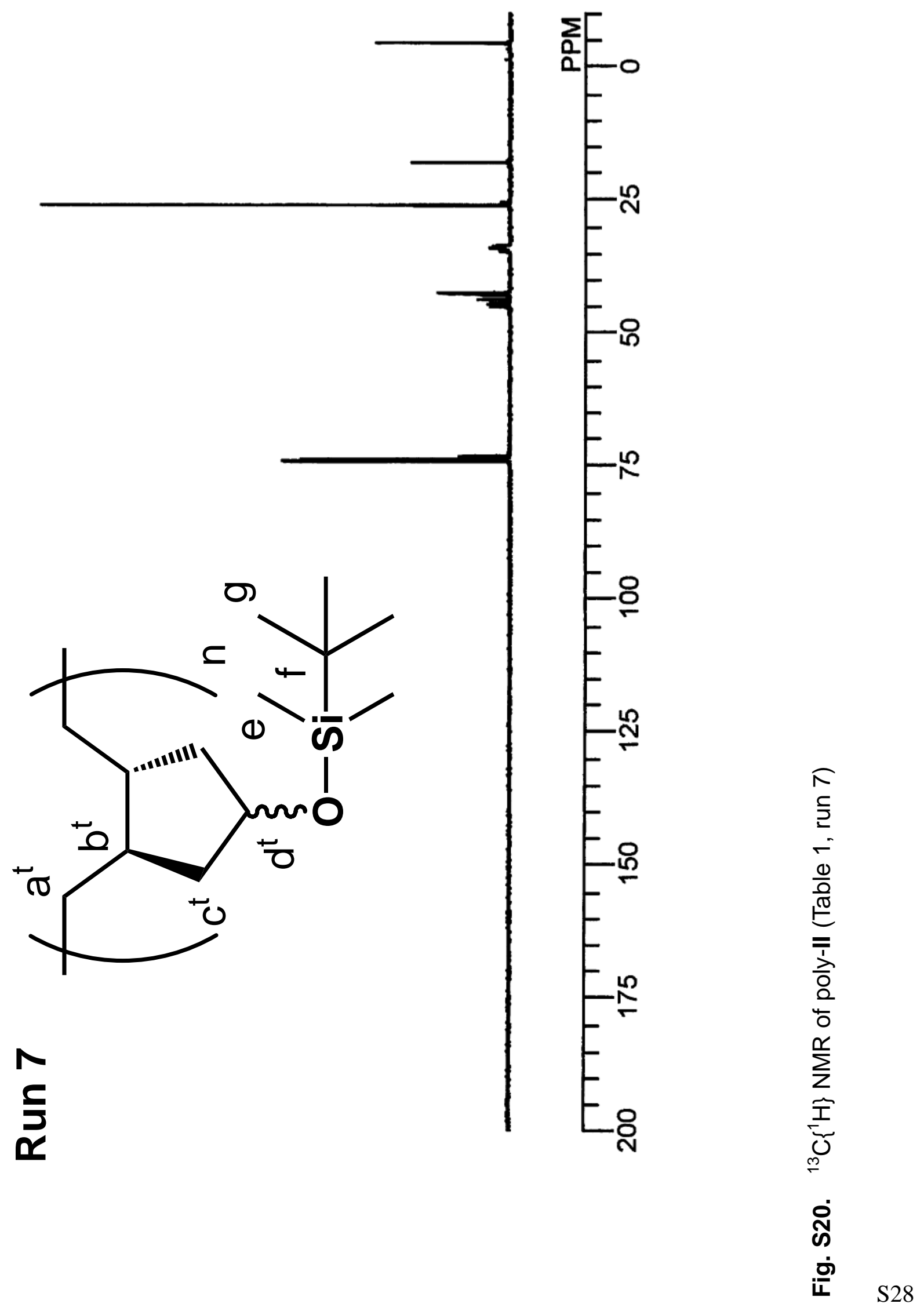




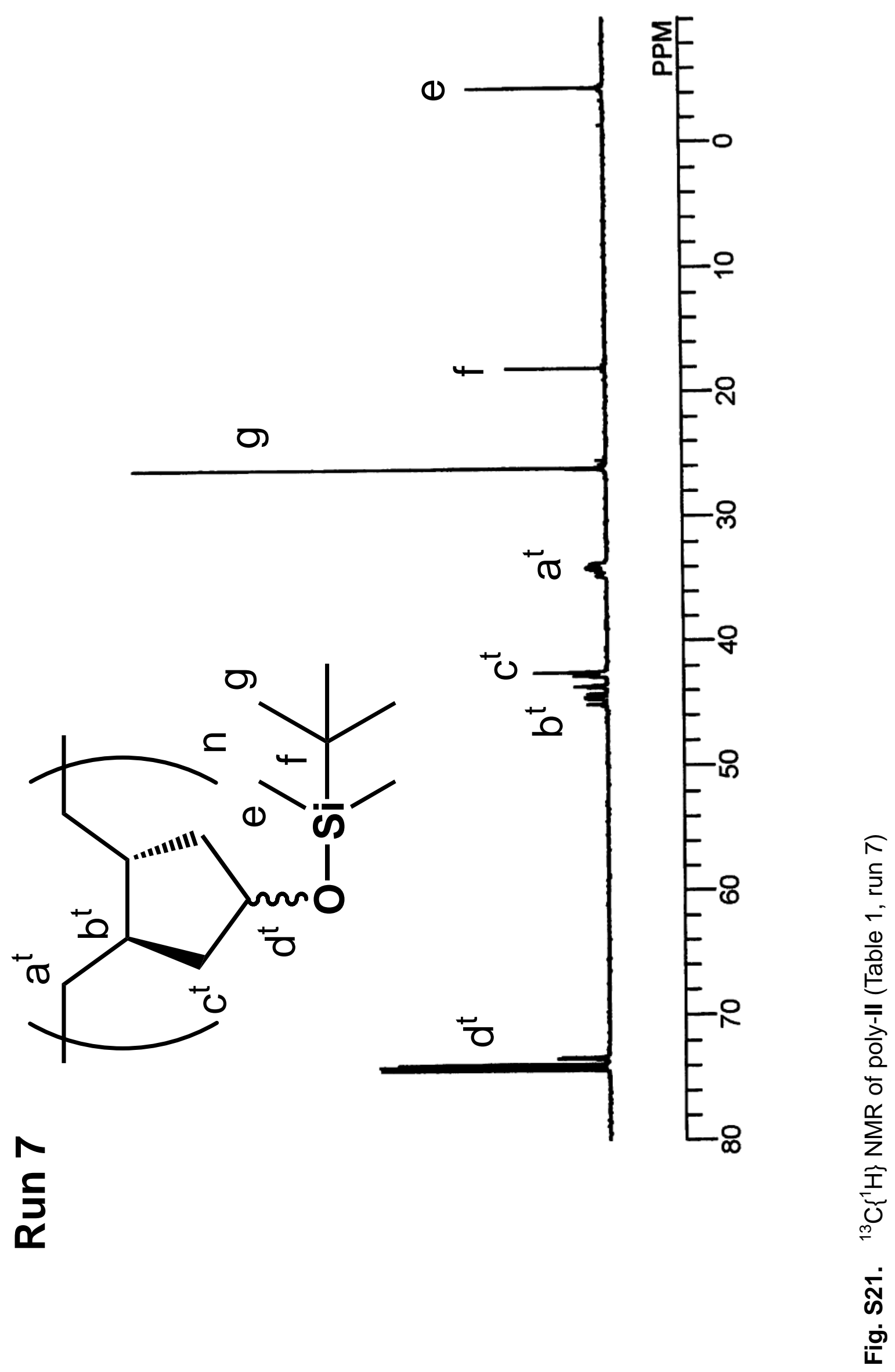




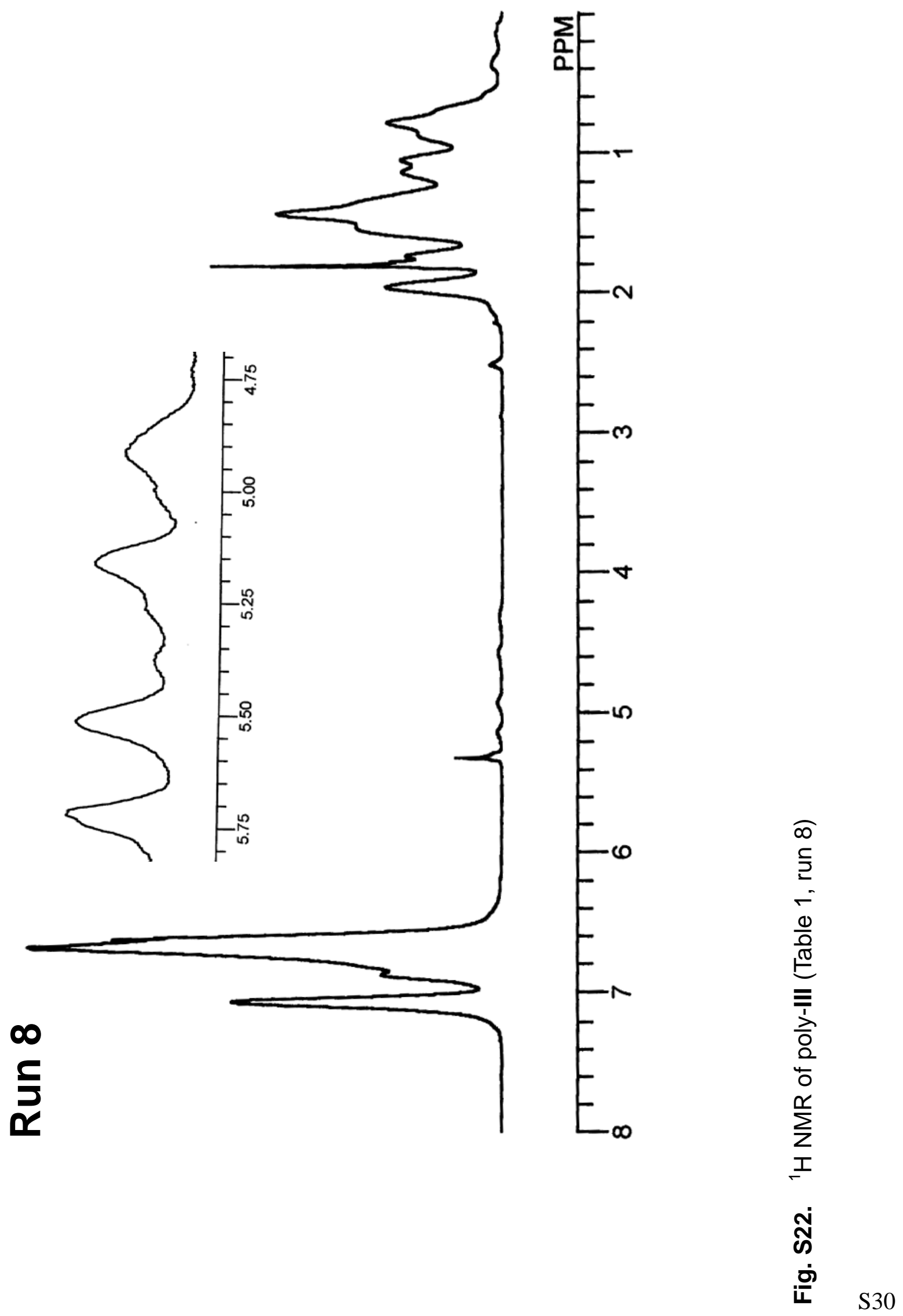




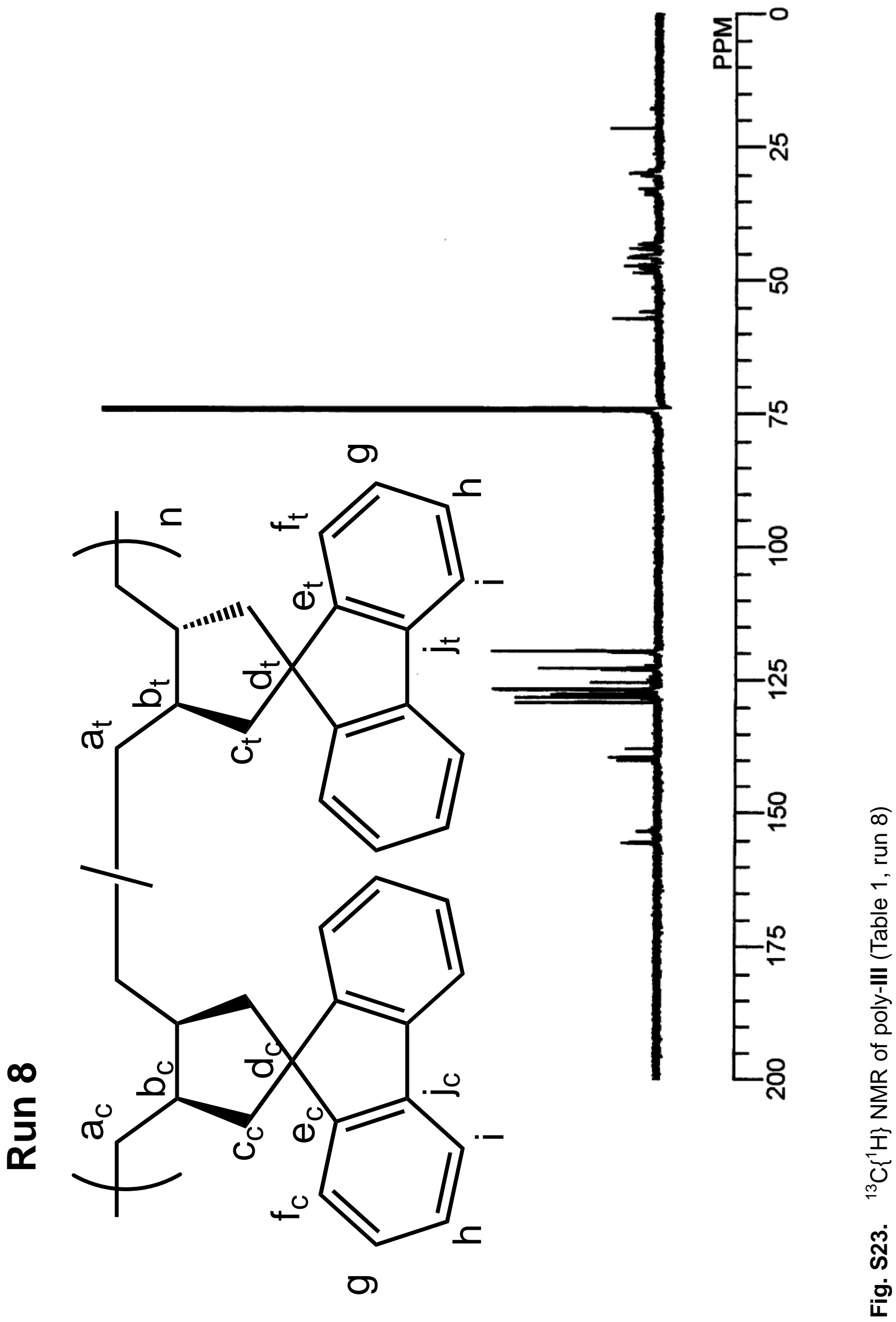




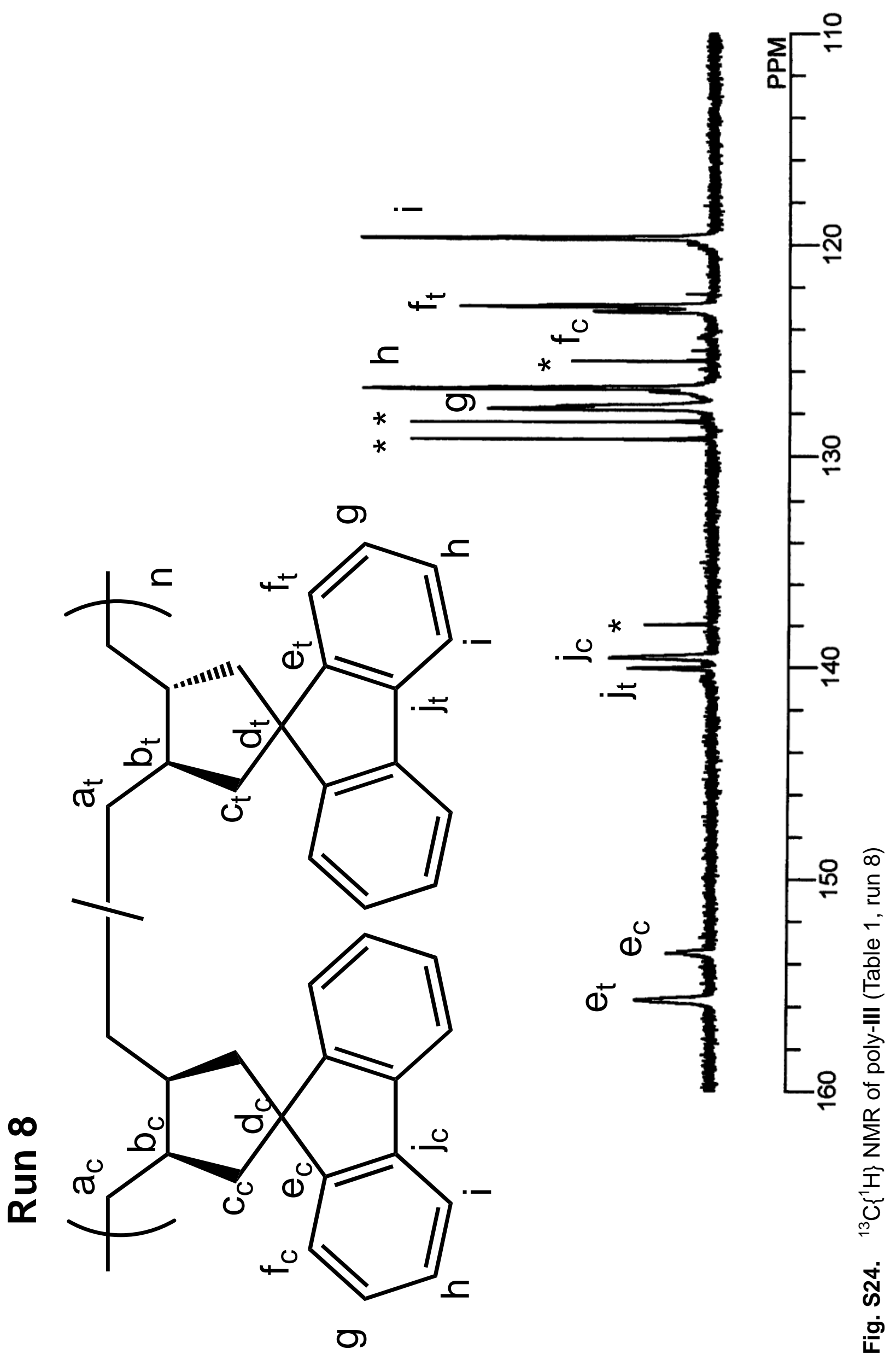

间 


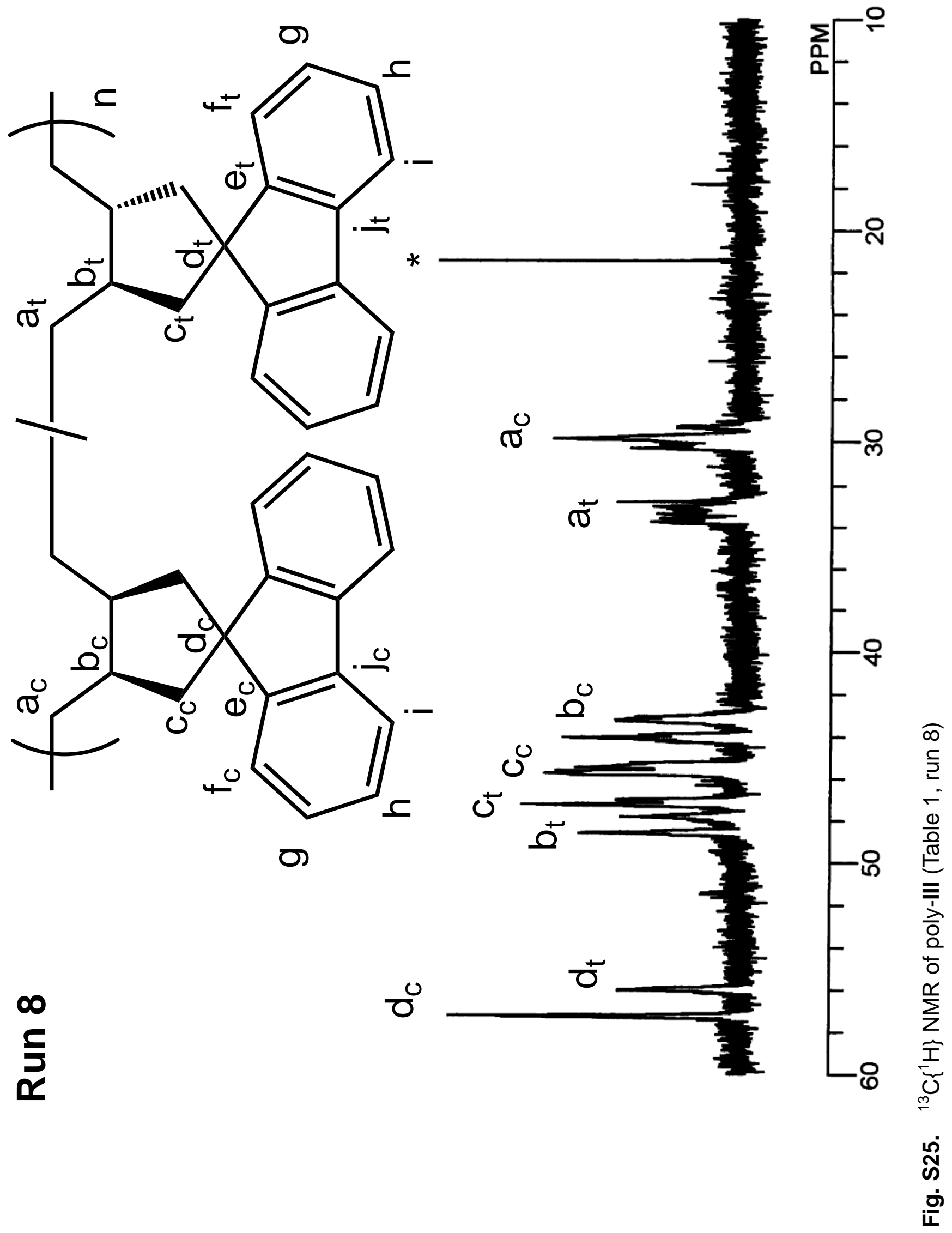




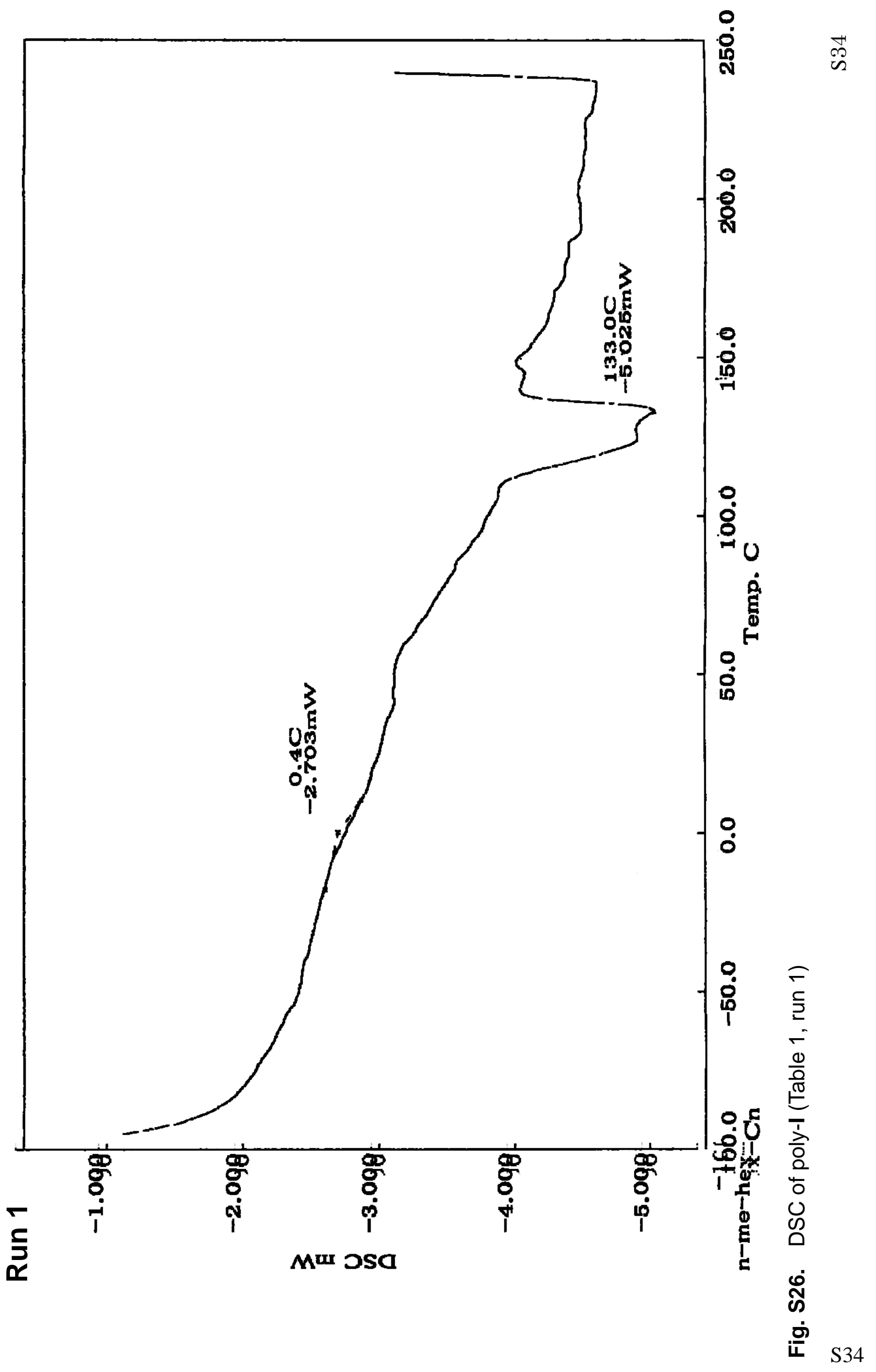




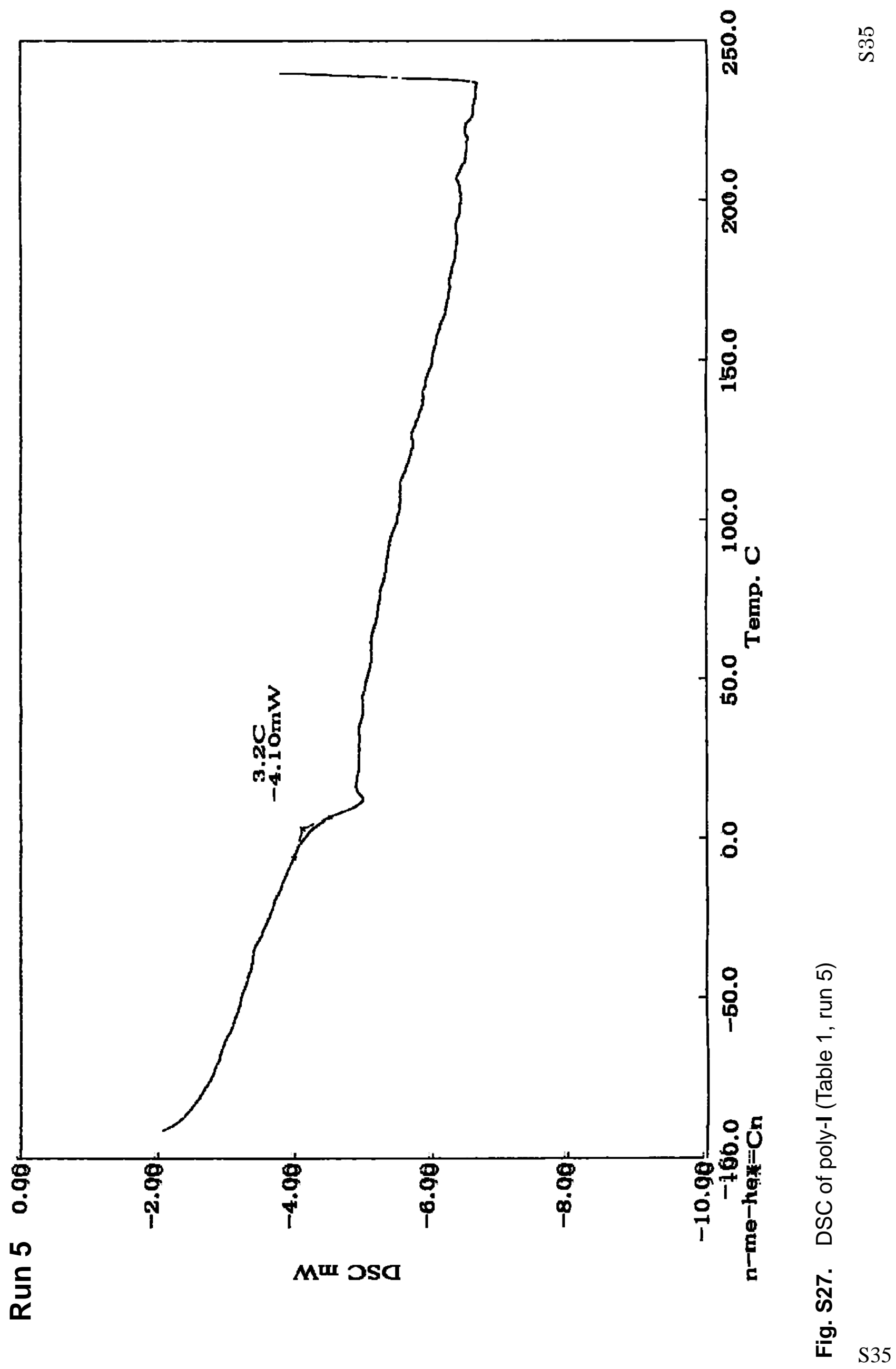

